\author{
BLANCA GUTIÉRREZ GALINDO \\ ESCUELA NACIONAL DE aRTES PLÁstiCAS, UNAM
}

\title{
Creatividad y democracia. Joseph Beuys y la crítica de la economía política
}

$\mathrm{E}$ n 1979 Joseph Beuys declaró que su proyecto artístico nació durante I956 y 1957 como "una investigación sobre el trabajo humano. No sólo el trabajo de los supuestos artistas, en tanto que especialistas en la sociedad, sino [como] una reflexión antropológica sobre la idea de creatividad". Del trabajo, precisó, "se desprenden los problemas de la libertad, de la autodeterminación por la creatividad, de la autoadministración, de la gestión [...] Todas estas cuestiones políticas muy importantes estaban implicadas en esa cuestión de base". 'También manifestó que su objetivo fue elaborar "una concepción del arte mucho más activa, en tanto que movimiento de liberación de la creatividad para escapar de los poderes que se ejercen contra los intereses del hombre". ${ }^{2}$ Se trataba, según sus palabras, de un "nuevo proyecto para conducir a la sociedad en su conjunto hacia una nueva forma". ${ }^{3}$

I. "Entrevista de Joseph Beuys con Bernard Lamarche-Vadel, agosto de I979", en Bernard Lamarche-Vadel, Joseph Beuys (Madrid: Siruela, 1994), 67-68. Las biografías de Adriani Götz, Winfried Konnertz et al., Joseph Beuys. Life and Works (Nueva York: Barron's, 1979) y de Heiner Stachelhaus, Joseph Beuys (Barcelona: Parsifal, 1990) establecen que en 1956-1957 Beuys sufrió una crisis nerviosa. En 1957 Beuys participó en el concurso para el memorial del antiguo campo de concentración Auschwitz-Birkenau.

2. "Entrevista de Joseph Beuys con Elizabeth Rona, octubre de I98I", en Lamarche-Vadel, Joseph Beuys, 82.

3. "Entrevista de Joseph Beuys con Elizabeth Rona, octubre de 198I", en Lamarche-Vadel, Joseph Beuys, 79-80. 
De esta manera definía lo que había venido siendo la premisa de su programa artístico desde finales de los años sesenta: "Todo hombre es un artista”. Este programa se sostuvo en el Concepto de Arte Ampliado y en el Proyecto de la Plástica Social. El primero se proponía la superación de la condición autónoma del arte a partir de la disolución de la diferencia entre arte y trabajo, y el segundo ambicionaba la transformación del arte en lugar de agencia política ciudadana. La forma como Beuys enuncia sus metas recuerda los proyectos vanguardistas de principios del siglo $\mathrm{xx}$, que con la energía creativa contenida en la institución del arte 4 intentaron fundar una nueva vida social cotidiana o Lebenswelt. 5 De manera semejante, Beuys ubica esta ambición como una posibilidad histórica a través de la ecuación entre creatividad y democracia. Su programa se refiere, por tanto, a la relación entre arte y procesos modernizadores en el horizonte histórico del capitalismo que parece haber barrido definitivamente con las posibilidades de una vida colectiva mejor.

En las páginas siguientes voy a sostener que al ubicar el concepto de trabajo en el centro de su "teoría plástica", Beuys elabora una crítica de la economía política y que, no obstante haber afirmado insistentemente que la suya era una reflexión antropológica - lo cual supuestamente se basaría en la idea de la existencia de "una naturaleza humana"-, su teoría ciertamente se articula en el horizonte histórico de la Guerra Fría en torno a una reflexión históricocrítica de la economía en sus formas capitalista y comunista. Dicho en otros términos, su teoría se refiere a la condición moderna del trabajo como trabajo alienado por la explotación en el capitalismo y la burocratización en el socialismo, en la misma medida en que se refiere a la condición moderna del arte como condición autónoma alienada de la vida social cotidiana. De esa manera su programa opera a partir de la necesaria interdependencia entre arte y sociedad.

$\mathrm{Al}$ concebir las capacidades humanas (Fähigkeiten) como capital reprimido en el trabajo alienado, la teoría de Beuys se vincula con aquella tradición del pensamiento occidental que de Fourier a Marcuse, pasando por SaintSimon y Marx, exploró las posibilidades utópicas del trabajo, cuya entrada en fase terminal Jürgen Habermas ubicaría precisamente al final de la década

4. Véase Peter Bürger, Teoría de la vanguardia (Barcelona: Península, I997).

5. El término Lebenswelt fue acuńado por Husserl en I9I7 para referirse a la pluralidad de sentidos de la experiencia en relación con los niveles de la realidad que conforman los ámbitos del evaluar, el desear y el actuar. Para la explicación de la relación entre mundo de la vida y sistema véase Jürgen Habermas, Teoría de la acción comunicativa II. Crítica de la razón funcionalista (Madrid: Taurus, 1987). 
de los años setenta, cuando en Europa tenía lugar el inicio de la crisis del estado de bienestar. ${ }^{6}$ De esta tradición, a pesar de haber negado a su proyecto cualquier dimensión utópica, participa también el cooperativismo de Rudolf Steiner, ${ }^{7}$ el pensador a quien la historiografía sobre la obra de Beuys se refiere reiteradamente como el origen de sus ideas y su proyecto.

A diferencia de quienes sostienen que las ideas económicas de Beuys provienen exclusivamente de Wilhelm Schmundt — quien a su vez se habría basado en las de Rudolf Steiner-, Thierry de Duve acertó al afirmar que durante la década de los años setenta Beuys elaboró "una verdadera economía política, sobre la cual pretendía fundar su teoría de la escultura social" y afirmó los vínculos de Beuys con el pensamiento de Karl Marx. No obstante, para poder descalificar la elaboración de la economía política de Beuys procede en primer lugar a hacer una lectura del concepto de trabajo de Marx como fuerza de trabajo (Arbeitskraft), y en segundo, y en consecuencia, atribuye a Beuys la comprensión de la idea de creatividad como "la capacidad de producir en general", como fuerza de trabajo. En ambos casos elimina la teoría del valor/trabajo y somete los conceptos principales de la economía política de Marx a una reducción semejante a la operada por el marxismo soviético en su afán de reprimir y desterrar de la teoría política la noción marxiana de alienación. Así, escribe: "Marx llama 'fuerza de trabajo' a esa facultad universal de producir valor, Beuys la llama creatividad. Por supuesto él no es el primero en darle ese nombre, lejos de eso, será más bien el último en poder hacerlo con convicción". Para Thierry de Duve, el arte de Beuys, su discurso, su actitud y sobre todo lo que él considera las dos caras de su personaje, "la cara sufriente" y la "cara utópica", son el canto del cisne de la creatividad, "el más poderoso de los mitos modernos". Por esa razón, continúa, la frase "Todo hombre es un artista" es lo que la modernidad artística nunca dejó de prometer, de esperar,

6. En 1984 Habermas analizó el fin de la sociedad del trabajo cuyo potencial utópico había alimentado también al Estado social, al que considera su última etapa. Seńaló el cambio de paradigma del trabajo hacia la comunicación: "el acento utópico se traslada del concepto del trabajo al de la comunicación. Me permito hablar de 'acentos' ya que, con el cambio de paradigma de la sociedad del trabajo a la de la comunicación, también ha variado la forma en la que nos vinculamos a la tradición utópica". Jürgen Habermas, "La crisis del estado de bienestar y el agotamiento de las energías utópicas", en Ensayos politicos (Barcelona: Península, 1988), I33.

7. Véase Rudolf Steiner, El nuevo orden social. La ciencia espiritual y la cuestión social. Los puntos esenciales de la cuestión social en la vida del presente y del futuro, versión en español de Francisco Schneider, en www.emagister.com, consultado el 6 agosto de 2010. 
de invocar como el cumplimiento de su horizonte emancipatorio: "Rimbaud lo dijo, Novalis lo pensó. Los estudiantes del 68, en París o en California, en Düsseldorf alrededor de Beuys, lo clamaban todavía y lo escribían sobre los muros. Su significado es el mismo desde los románticos alemanes: 'la imaginación al poder'. Eso nunca se convirtió en realidad, al menos en ese sentido". ${ }^{8}$

Como se ve, De Duve reduce el concepto de creatividad a una sola de sus posibilidades interpretativas: aquella que en el romanticismo representó la promesa de democratizar el arte en razón de que, "potencialmente", todo hombre puede ser un artista en el sentido tradicional de ejercer alguna de las bellas artes. 9 Pero la ecuación de Beuys es la opuesta: el ser humano es un artista por el sólo hecho de serlo, de su pertenencia al género humano y, por ello, de ser capaz de actividad práctica. La afirmación "Cada hombre es un artista" (Jeder Mensch ist ein Künstler) no se refiere al ámbito de lo posible, sino al de lo real, y es ahí, precisamente, donde aparece la necesidad de explicar las razones por las que si todo hombre es un artista, en la sociedad moderna sólo algunos ostentan ese estatuto.

La reducción operada por De Duve se explica por la descalificación de la economía política de Beuys, vale decir, porque en lugar de explicar su programa a la luz de la crítica de la alienación y en el horizonte de la tradición que ve en las capacidades reprimidas por el capitalismo un potencial de transformación social e histórica, lo subsume el concepto de creatividad al horizonte de la Bohemia del siglo xix. ${ }^{\text {IO }}$ De ese modo, al descargar la propuesta de ampliación del arte de su dimensión negativa, De Duve la desvincula de sus relaciones con las circunstancias sociales, políticas, económicas e históricas de la Alemania de las décadas de los años sesenta y setenta.

Este trabajo se divide en dos partes. En la primera estudio el concepto de trabajo de Beuys y lo que él llamó "antropología de la creatividad" a la luz

8. Thierry de Duve, "Joseph Beuys ou le dernier des prolétaires", en Cousus de fil d'or: Beuys, Warhol, Klein, Duchamp (Villeurbanne: Art Édition, 1990), 20. Este texto fue publicado en October, núm. 45 (verano, I988) junto con los textos de Eric Michaud, "The Ends of Art According to Beuys", y Stefan Germer, "Haacke, Broodthaers, Beuys".

9. En el texto "When Form Has Become Attitude and Beyond" (I994), Thierry de Duve explica las diferencias entre talento y creatividad y ubica la creatividad como el paradigma del arte moderno (Theory in Contemporary Art since 1985, eds. Zoya Kocur y Simon Leung [Óxford: Blackwell, 2005]). Sobre la historia del concepto de la teoría de la creatividad véase Wladyslaw Tatarkiewicz, "La creatividad. Historia del concepto", en Historia de seis ideas. Arte, belleza, forma, creatividad, mimesis, experiencia estética (Madrid: Tecnos, 1997).

ı. De Duve, "Joseph Beuys ou le dernier des prolétaires", IO-I3. 
de la teoría del valor/trabajo de Marx. En la segunda analizo el concepto de trabajo como parte de los cimientos sobre los cuales se sostiene la condición autónoma del arte como práctica especializada en la experiencia de lo bello durante la modernidad. En las dos expondré los argumentos con que Beuys sostiene la posibilidad de llevar a cabo la superación (Aufhebung) del arte en la vida a partir de la superación de la economía capitalista.

\section{Arte y creatividad}

Casi al final del "Discurso sobre el propio país: Alemania" (Reden über das eigene Land: Deutschland), leído el 20 de noviembre de 1985 en Múnich, ${ }^{\text {II }}$ dos meses antes de su muerte, Beuys afirmó: “¡El dinero no es un valor económico! Cuando el poder del dinero no cesa de sepultar todo lo que está inspirado por la libertad y la democracia, cuando el poder del dinero no cesa de destruir el ideal, debemos lanzarnos a la boca de este dragón y empuñar el concepto de capital. Es preciso que nos batamos de una manera muy decidida contra el concepto de capital". ${ }^{\text {I2 }}$

Notemos, para comenzar, que en esta declaración el artista no se refiere al capitalismo, sino al concepto de capital. Para Beuys, el arte es un proceso dinámico que supone la intervención del pensamiento, el sentimiento y la voluntad. La actividad plástica, que se define por su carácter formador, nos

II. El texto se leyó en los Kammerspiele de Múnich dentro del ciclo Reden über das eigene Land: Deutschland (Discurso sobre el propio país: Alemania). La conferencia fue corregida por el artista y publicada bajo el título del evento. La primera publicación tuvo lugar en Reden über das eigene Land: Deutschland, t. 3 (Múnich: Bertelsman Verlag, 1985), 37. Existen varias versiones en español: "Discurso sobre el propio país: Alemania", en Joseph Beuys. Ensayos y entrevistas, ed. Bernd Klüser (Madrid: Síntesis, 2006); "Discurso sobre mi país", en Carmen Bernárdez Sanchís, Joseph Beuys (Hondarribia [Guipúzcoa]: Nerea, 1999); "Hablar del propio país: Alemania", en Joseph Beuys. En torno a la muerte de Joseph Beuys. Necrologías, ensayos, discursos (Bonn: Inter-Nations, 1986). Utilizaré la traducción incluida en la antología de Bernd Klüser por considerarla más apegada al original en alemán. La traducción publicada en el libro de Carmen Bernárdez Sanchís reproduce las connotaciones nacionalistas de la traducción al francés del "Discours sur mon pays", publicado en Joseph Beuys, Par la présent, je n’appartiens plus à l'art (París: L’Arche, I988), I9-43. También la publicación del texto por la FIU-Verlag en 2002 reproduce esas connotaciones al haber titulado el texto Sprechen über Deutschland: Rede vom 20. November 1985 in den Münchner Kammerspiele/Joseph Beuys (Wangen, Allgäu: FIU Verlag, 2002), 5-8.

I2. Beuys, "Discurso sobre el propio país", en Joseph Beuys, ed. Klüser, 2 I I. 
dice, "comienza con el lenguaje y el pensamiento, que mediante el lenguaje aprende a formar conceptos capaces de insuflar a la forma el sentimiento y la voluntad". Es éste el proceso que hace posible la aparición de "imágenes que apuntan al futuro" y así "primero tendría lugar una forma interna en el pensamiento y el conocimiento y ésta podría expresarse después en la acción de la sustancia material", en "la materia firme que se observa en el trabajo". Así pues, dice: "Según mi manera de ver las cosas la condición necesaria para el futuro de una escultura es que aparezca una forma interior primero en el pensamiento y el conocimiento, y que pueda expresarse en la huella de la materia, de una materia sólida". ${ }^{\text {3 }}$

Como vemos, la creación se describe aquí como la confluencia entre pensamiento y acción que permite a los seres humanos dar forma a su mundo y a su relación con él. Beuys se refirió a ese proceso como "proceso paralelo". Con ello quiso significar los dos polos de la actividad artística, el espiritual-intelectual (geistig) y el material. El pensamiento es la energía primaria, "principio originario de la creación", ese "desencadenador revolucionario", la más importante "herramienta artística" de la cual dependen las posibilidades de actuar en y sobre el mundo. El pensamiento es, pues, el origen de las formas expresadas en la arquitectura, la agricultura o en cualquier actividad humana, remunerada o no, considerada como "productiva" o "improductiva" ${ }^{4}$ y es, en sí mismo, un proceso plástico. Pero este proceso depende de la materialidad del cuerpo y su relación con la materia, es decir, involucra no solamente elementos psíquicos sino también físicos y posee una dimensión biológica a la vez que sensible:

El pensamiento es un proceso escultórico y la expresión de las formas pensadas en el lenguaje es también arte. Esta totalidad de la creatividad humana — comenzando con los sentimientos y los pensamientos y su expresión en un material especial, el material del lenguaje, para el que se necesita el cuerpo y las herramientas físicas, la lengua, la laringe, el aire, las ondas sonoras, el oído de otras personas, todo esto tiene que ver con la idea de escultura en el futuro. ${ }^{\text {Is }}$

Este proceso, el cual Beuys intentó plasmar plásticamente en numerosos dibujos como Gespräch (Conversación) (I974) (fig. I), también se encuentra en

13. Beuys, "Discurso sobre el propio país", en Joseph Beuys, ed. Klüser, 200.

I4. Comúnmente se considera trabajo productivo el que produce plusvalor.

15. "Interview with Kate Hosfield", en Energy Plan for the Western Man. Joseph Beuys in America, ed. Carin Kuoni (Nueva York: Four Walls Eight Windows, 1990), 73. 
I. Joseph Beuys, Gespräch (Conversación), I974, dibujo con bolígrafo, $35.7 \times 27.2$. $\mathrm{cm}$, tomado de Joseph Beuys, Joseph Beuys: Zeichnungen, Tekeningen, Drawings (Múnich: Prestel, I980). D. R. (C) Joseph Beuys/ BILDKUNST/SOMAAP/ México/2013.

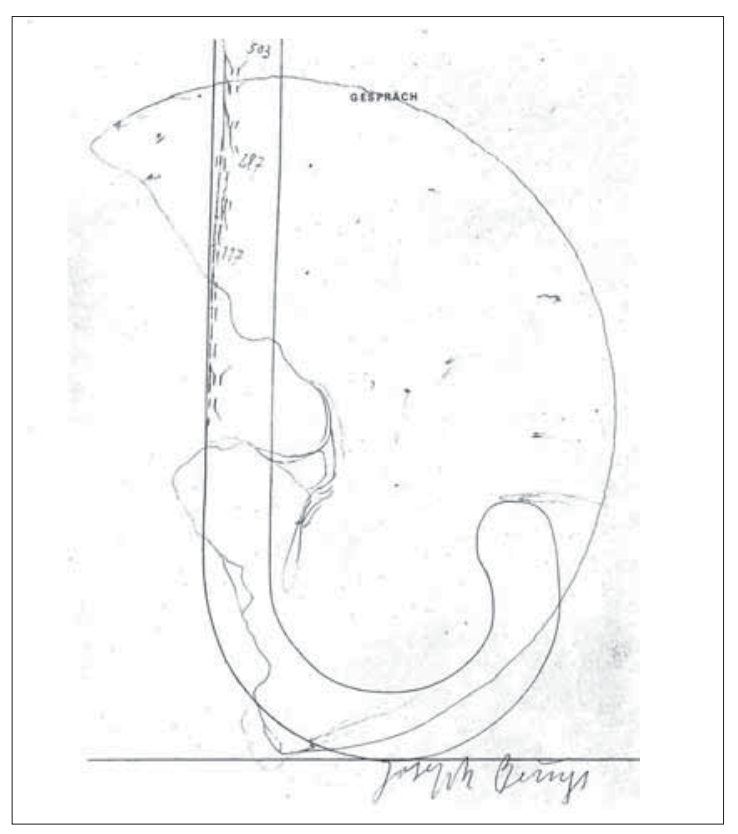

la base de la idea de trabajo humano o actividad práctica que involucra por igual al pensamiento y a la acción, y se refiere a los procesos biológicos de la vida, al metabolismo entre hombre y naturaleza. La premisa del arte ampliado "Cada ser humano es un artista" se refiere, por tanto, a la condición productiva del hombre, es decir, a su condición práctica. ${ }^{16}$

I6. Eric Michaud ve en la preocupación de Beuys por los procesos del trabajo uno de sus supuestos vínculos con el nacionalsocialismo y la compara con "la fundación del Departamento de la Belleza del Trabajo (Schönheit der Arbeit) [que] testimonia la voluntad del nacionalsocialismo de identificar el trabajo con la creación de la obra de arte total del Reich eterno, haciendo de cada alemán un artista". También señala que "la fórmula de Beuys, según la cual 'cada hombre es un artista' que concurre en la edificación del orden social —la obra de arte total del futuro - , hace de este orden por venir un mito análogo al del Reich eterno: una promesa movilizadora de redención para todos, por poco que todos se conviertan en artistas, es decir, identificando la política con 'la formación de un mundo visto como escultura'". "De Fluxus à Beuys: la fascination du politique", en L'Oeuvre d'art totale, ed. Elie Konigson (París: CNRS Éditions, 2002), 299. Sobre la relación entre nacionalsocialismo y arte véase, por ejemplo, el libro del propio Eric Michaud, The Cult of Art in Nazi Germany (Stanford, California: Stanford University Press, 2004). 


\section{Trabajo}

Giorgio Agamben ha explicado que los griegos distinguieron tres modalidades del "hacer" humano en las cuales el trabajo ocupó el lugar más bajo en la jerarquía de la vida activa. En el trabajo, el hombre estaba obligado a buscar permanentemente su sustento, por lo cual este sometimiento a la necesidad lo igualaba con los animales y era, por ello, incompatible con la condición del hombre libre. Los griegos distinguían, además, entre poiesis (poiein, producir, en el sentido de llevar a ser) y praxis (prattein, hacer en el sentido de realizar). Mientras esta última tenía en su centro la idea de "voluntad que se expresa inmediatamente en la acción", en el centro de la poiesis estaba "la experiencia de la pro-ducción hacia la presencia, es decir, el hecho de que en ella algo pasase del no-ser al ser, de la ocultación a la plena luz de la obra”. La singularidad de la poiesis no residía en el proceso práctico, sino en ser una forma de la verdad entendida como des-velamiento (aletheia). Por el contrario, la raíz de la praxis se hundía en la condición del hombre en cuanto animal, ser viviente, principio del movimiento (la voluntad entendida como unidad de apetito, deseo y volición que caracteriza a la vida). ${ }^{17}$ Así, mientras el presupuesto del trabajo era la desnuda existencia biológica, el proceso cíclico del cuerpo humano (cuyo metabolismo y cuyas energías dependen de los productos elementales del trabajo), la praxis se definía por la orientación hacia la realización de fines y la poiesis era el espacio donde el hombre encontraba su certeza y aseguraba la libertad y la duración de su acción. ${ }^{\mathrm{I}}$

Pero en la cultura occidental ha tenido lugar un proceso por el cual la diferencia entre estas tres modalidades del "hacer" humano se ha ofuscado. Este proceso, explica Agamben, se inicia con la traducción al latín de la poiesis como una forma de agere, es decir, como un actuar que pone en obra un operari, lo cual para los romanos va a involucrar la producción voluntaria de un efecto. Se completa este proceso con la aparición del pensamiento teológico cristiano que piensa al ser supremo como actus purus, con lo cual vincula la metafísica occidental a la interpretación del ser como evidencia concreta y acto. Es así, dice Agamben, como en la época moderna desaparece la diferencia entre poiesis y praxis y "el hacer" del hombre se determina como actividad productora de un efecto real (el opus del operari, el factum del facere, el actus

I7. Giorgio Agamben, El hombre sin contenido (Barcelona: Altera, 2005), II2-I I3.

I8. Agamben, El hombre sin contenido, II3. 
del agere) cuyo valor se aprecia en función de la voluntad de lo expresado en ella, es decir, en relación con su libertad y su creatividad. ${ }^{19}$

Paralelamente, el trabajo, que ocupaba el lugar más bajo en la jerarquía de la vida activa, asciende a valor central y denominador común de cualquier actividad humana. Esta ascensión la explica Hanna Arendt a partir de la distinción entre labor y trabajo, entre homo laborans y homo faber. La labor es el tipo de trabajo ligado a la esclavitud de la necesidad cuyo carácter doloroso está presente incluso en las palabras que lo designan en diversas lenguas europeas - como el griego, el latín, el francés o el alemán-, las cuales diferencian entre labor y trabajo y donde los equivalentes de "labor" tienen un inequívoco sentido de dolor y molestia. Así, en alemán, la palabra Arbeit se aplicó originariamente a la labor campesina ejecutada por los siervos y no al trabajo del artesano al que se llama Werk. ${ }^{20}$ La diferenciación entre trabajo y labor atañe, por tanto, a la distinción entre "manos que trabajan" y "cuerpo que labora", y guarda algo de aquella diferenciación griega entre el trabajo del artesano (en alemán Handwerker) y el trabajo de los "esclavos y animales que atienden con su cuerpo a las necesidades de la vida". Mientras el trabajo es productivo en tanto agrega nuevos objetos al mundo, la labor está ligada directamente a la vida, es reproductiva o, si se prefiere, no "produce" más que vida, y se refiere a la fertilidad. Así pues, mientras el primero está relacionado con los objetos de uso, la segunda lo está con el consumo. Pero en la modernidad, explica Arendt, la labor (Arbeit) experimentó un "repentino y espectacular ascenso" y se convirtió en "la más estimada de las actividades humanas" cuando "Locke descubrió que la labor es fuente de toda propiedad. Siguió su curso cuando Adam Smith afirmó que la labor era la fuente de toda riqueza y alcanzó su punto culminante en el 'sistema de la labor' de Marx, donde ésta devino fuente de toda productividad y expresión de la misma humanidad del hombre". ${ }^{21}$

Para Arendt, en este proceso permanece inalterable la vinculación del trabajo con el ciclo biológico del organismo. No obstante que Locke, Smith y Marx "igualaron el trabajo con la labor", explica Hanna Arendt, sólo Marx se interesó por la labor como tal. Los tres autores consideraron la labor como la suprema capacidad del hombre para construir el mundo, pero fue Marx quien forjó su definición en el metabolismo "entre el hombre y la naturaleza", "en el

19. Agamben, El hombre sin contenido, II4.

20. Hanna Arendt, La condición humana (Barcelona: Paidós, 2005), I48, n. 3.

2I. Arendt, La condición humana, I22. 
que queda inmediatamente 'incorporado' el producto, consumido y aniquilado por el proceso vital del cuerpo". ${ }^{22}$ De ello resulta que conceptos como productividad y fertilidad han terminado también por igualarse.

Fue así como la modernidad ubicó el trabajo en el lugar central de la actividad humana y convirtió al homo faber, al productor — en cuya actividad se unen manos y cuerpo-, en el centro de todos los procesos históricos y sociales. Así, todo "hacer" humano ha llegado a interpretarse como actividad productora concreta, en la cual se incluyen el arte y las actividades propias de los ciudadanos libres griegos — como el ejercicio del pensamiento, el discurso y la contemplación abstracta, además de las actividades relacionadas con la polis, o, en los términos de Hanna Arendt, las que constituyen el verdadero mundo de lo humano, las que nos constituyen como agentes: hablar $y$ actuar. ${ }^{23}$ Agamben considera que en ese proceso permanece inalterable la voluntad creadora, la cual, como hemos visto, es característica de la praxis y terminó por eclipsar la esfera de la poiesis.

Pero que esta modalidad del trabajo se convirtiera en el hecho social más importante, casi total, en la definición de la existencia humana tiene que ver, también, con el desarrollo y consolidación del capitalismo. El trabajo, en su forma moderna, como metabolismo entre hombre y naturaleza y producto de la voluntad, se constituyó como tal en el transcurso de los siglos XVIII y XIX a partir de la división social del mismo y de la relación entre capital y trabajo, lo cual convirtió a este último en trabajo remunerado. ${ }^{24}$

Es pues el concepto moderno, marxista, del trabajo el que sustenta el programa de Beuys. En el texto de un pizarrón fechado en diciembre de 1985 (fig. 2) escribió:

No soy marxista, pero quizá quiera más a Marx que los numerosos marxistas que no hacen sino creer en él. Me di a la tarea de desarrollar lo que comprendí gracias

22. Arendt, La condición humana, I23.

23. Arendt, La condición humana, 205-276.

24. Johannes Rohbeck seńala que otro presupuesto histórico de la forma moderna del trabajo fue la separación de trabajo y familia en dos ámbitos vitales diferentes, de los cuales el trabajo ocupó el lugar central, sobre todo en la vida masculina. "Radicalización de la modernidad", en La modernidad en el debate de la historiografía alemana, coord. Silvia Pappe (México: Universidad Autónoma Metropolitana/Consejo Nacional de Ciencia y Tecnología, 2004), I93-I94. 
2. Joseph Beuys, Pizarrón, diciembre de 1985 , I.5 $\times$ Im. Foto: André Heller, Hamburgo, verano de i987. D. R. (C) Joseph

Beuys/BILDKUNST/SOMAAP/ México/20I3.

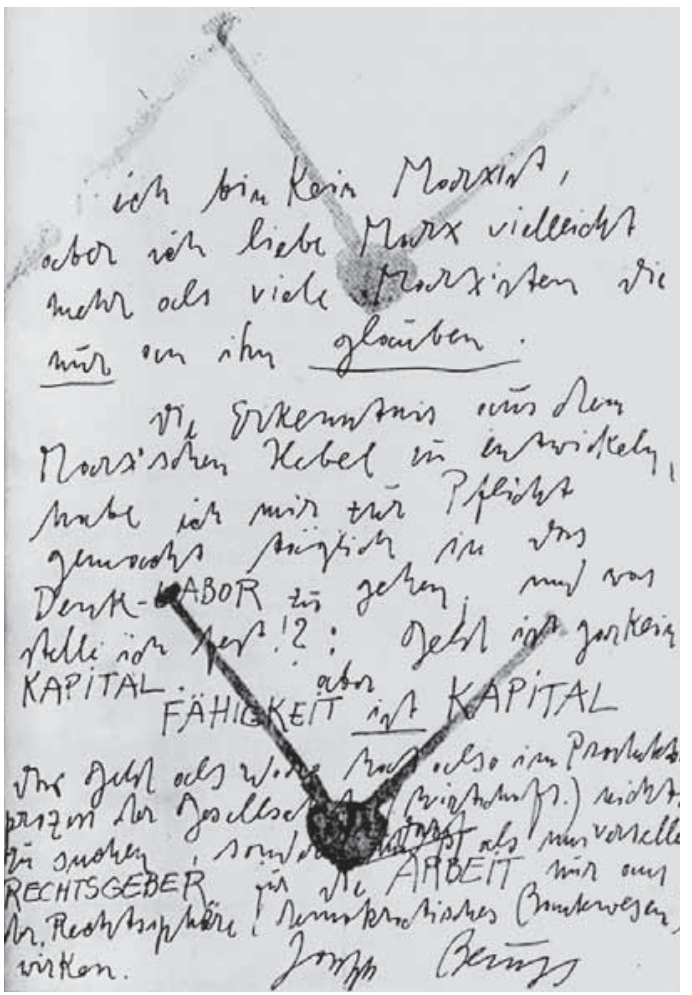

a la palanca marxiana, a saber, ir cada día al LABORATORIO CONCEPTUAL [DENKLABOR]: y ¿qué es lo que constato?

El dinero no es para nada capital. Es la capacidad la que es el CAPITAL [Fähigkeit ist Kapital]."25

25. La traducción literal de Denk Labor sería "Laboratorio del pensamiento". En el último párrafo del pizarrón se lee: "El dinero en tanto que mercancía no tiene nada que ver con el proceso de producción de la sociedad (la economía), sino en tanto que FUNDADOR DE DERECHO para el TRABAjo. Es necesario y permitido que reaccione a partir de esta esfera de derecho (sistema bancario democrático)". Joseph Beuys, Qu'est-ce que l'argent? Un dèbat (París: L'Arche, 1994), 32. Sobre el uso de los pizarrones en la obra de Beuys véase FranzJoaquim Verspohl, Joseph Beuys. Das Kapital Raum 1970-1977. Strategien zur Reaktivierung der Sinne (Fráncfort del Meno: Fischer Taschenbuch Verlag, 1984). También Joseph Beuys y Rudolf Steiner, Imagination, inspiration e intuition (Victoria, Australia: National Gallery of Victoria, 2007). 
Refiriéndose a la división geopolítica entre el este comunista y el oeste capitalista, producto de la Guerra Fría, Beuys declaró que "la doctrina de Marx no es suficiente en sí misma [sino que] es necesario elaborar alguna otra cosa para liberar a todos los individuos conscientes" ${ }^{26}$ En efecto, a pesar de que en numerosas ocasiones criticó a Marx y al marxismo, el artista acudió al autor de El capital a la hora de definir sus conceptos económicos, a principios de los años setenta. ${ }^{27}$ Esto ocurrió cuando Alemania Federal era gobernada por los socialdemócratas, quienes pusieron en marcha una política económica fundada en presupuestos keynesianos — basados en la convicción de que el Estado puede ejercer cierto control sobre los ciclos económicos y los periodos de crecimiento-y las iniciativas ciudadanas y los nuevos movimientos sociales, como el feminismo, el pacifismo y el ambientalismo, se estaban reorganizando después de la disolución del movimiento estudiantil. En 1972, en una de sus intervenciones en el Büro der Organisation für direkte Demokratie durch Volksabstimmung, odD (Oficina de la Organización para la Democracia Directa mediante Referéndum), Beuys manifestó su intención de corregir el marxismo por medio de un complemento. Declaró que en tanto su proyecto partía "no de los medios de producción, sino de la libertad del ser humano

26. Joseph Beuys, "La mort me tient en évil, interview d'Achille Bonito Oliva”, en Par la présent, je n'appartiens plus à l'art (París: L'Arche, I988), 67.

27. El origen de estos conceptos ha sido ubicado en el pensamiento del economista alemán Wilhelm Schmundt (1898-I992), autor del libro Der soziale Organismus in seiner Freiheitsgestalt (El organismo social en su forma libre), publicado en I968, en el cual desarrolla los principios de una economía basada en las habilidades de acuerdo con las ideas de Rudolf Steiner. Schmundt también llevó a cabo una redefinición de las interacciones entre trabajo, ingreso, propiedad, dinero y capital. Con base en el hecho de que en los años setenta Beuys se refirió a sus formulaciones y sostuvo un encuentro con él en 1973 en Achberg, se le ha declarado como el origen de sus ideas económicas. En I976, un año antes de la realización de Bomba de miel en el lugar de trabajo, Beuys le escribió una carta donde le hace saber que sigue el debate acerca de sus ideas. Véase P.S. Ulrich Rösch, "On ne peut comprendre Joseph Beuys que lorsqu'on l'a déjà compris. Explications sur le concept d'argent et de capital de Joseph Beuys", en Beuys, Qu'est-ce que l'argent?, 64, y 83-Ioo. Sobre las relaciones entre Beuys y Schmundt véanse: "Conferencia tercer camino (Dritter Weg) de 1973 " y el "Llamamiento a la alternativa” (Aufruf zur Alternative), en Joseph Beuys, ed. Klüser. También Lukas Beckman, "The Causes Lie in the Future", en Joseph Beuys. Mapping the Legacy, ed. Gene Ray (Nueva York: D.A.P./The John and Mable Ringling Museum of Art, 200I), 9I-I I 2. Johannes Stüttgen afirma que Beuys no habría llegado a su famosa fórmula arte=capital sin las ideas de Schmundt (Kunst des sozialen Bauens [Wagner: fiu Verlag, I973], I6, en Beckman, "The Causes", en Joseph Beuys, ed. Ray). 
como criatura que se autodetermina", era "un complemento del marxismo", y lo definió como "humanismo libertario". ${ }^{28}$

\section{Creatividad}

Como se señaló al principio de este texto, Beuys concibe la totalidad de la creatividad humana, los sentimientos y los pensamientos, y su expresión en el lenguaje, como un proceso que supone la intervención del cuerpo y "las herramientas físicas, la lengua, la laringe, el aire, las ondas sonoras, el oído de otras personas". ${ }^{29} \mathrm{Su}$ punto de partida es, así, la condición moderna del trabajo explicada en párrafos anteriores. De manera que, al igual que para Marx, para quien el trabajo pone en acción las fuerzas naturales integrantes de la corporeidad del hombre: "los brazos y las piernas, la cabeza y la mano" y de esta manera "desarrolla las potencias que dormitan en él", ${ }^{\circ}$ para Beuys, el trabajo supone la actividad del "cuerpo", la "lengua", la "laringe". Coincide, en consecuencia, con el autor de El capital al definir el proceso del trabajo humano como labor e igualmente como praxis, es decir, como un proceso en el cual intervienen el cuerpo en su materialidad y la voluntad, en tanto síntesis de pensamiento, intención y acción. Veamos cómo lo explica Marx:

Una araña ejecuta operaciones que semejan a las operaciones del tejedor, y la construcción de los panales de las abejas podrían avergonzar, por su perfección, a más de un maestro de obras. Pero, hay algo en lo que el peor maestro de obras aventaja, desde luego, a la mejor abeja, y es el hecho de que antes de ejecutar la construcción, la proyecta en su cerebro. Al final del proceso de trabajo, brota un resultado que antes de comenzar el proceso existía ya en la mente del obrero, es decir, un resultado que tenía ya existencia ideal. El obrero no se limita a hacer cambiar de forma la materia que le brinda la naturaleza, sino que al mismo tiempo realiza en ella su fin, fin que él sabe que rige como una ley las modalidades de su actuación y al que tiene necesariamente que modelar su voluntad. ${ }^{31}$

28. Clara Bodenmann-Ritter,Joseph Beuys. Cada hombre, unartista (Madrid:Visor, 1995), 56. 29. "Interview with Kate Hosfield", en Energy Plan, ed. Kuoni, 73.

30. Carlos Marx, El capital. Crítica de la economía politica, sección tercera, cap. V, "Proceso de trabajo y proceso de valorización”, vol. I (México: Fondo de Cultura Económica, 1974), I30. 31. Marx, El capital, I30-I3I. 
El trabajo es, así, capacidad creadora que socializa la naturaleza con arreglo a fines históricos - en cuanto pertenecientes al reino de lo humano. Como se ve, para Beuys, y para Marx, los procesos de transformación de la materia se refieren a los procesos biológicos de la vida. Pero si en la labor, como en la vida animal, el trabajo se confunde con la propia vida - como en el caso de las abejas-, en los seres humanos se realiza en forma multidimensional en tanto actividad cognitiva, expresiva e instrumental..$^{32}$ Pensar y hacer de acuerdo a objetivos es una actividad que contiene y construye la energía creativa que funda al hombre y al mundo como mundo social-humano.

Como se señaló, para Beuys el trabajo comienza con la elaboración de conceptos, ideas y representaciones que habrán de definir los fines y ordenar la acción. La autoconciencia de este proceso permite comprender que no solamente somos seres biológicos, seres materiales, sino, en principio, también somos seres espirituales (geistig) en tanto somos capaces de pensamiento, sentimiento, imaginación, voluntad. En otras palabras, no sólo somos laborantes, somos también productores. Y es el pensamiento — al cual Beuys llama sustancia espiritual o sustancia interior- el que en su flujo moviliza "el calor", identificado por Beuys como el principio de todos los valores económicos (fig. 3). En tanto condición y motor del obrar humano, el pensamiento supone la puesta en movimiento de fuerzas vitales en un sentido relacional, por lo cual "no se convertirá en un proceso de calor más que si se comunica a otros, que si uno escucha, digamos, aquello que los otros hombres producen por su lado". 33 Así quiso expresarlo en sus Esquinas de grasa:

el carácter real del calor existente es un elemento fluido inicial, que afecta a la grasa y así ésta se funde. De este elemento indefinido de movimiento, mediante un elemento de movimiento en disminución, surge una forma que se manifiesta en una configuración abstracta, geométrica. Ésta es una práctica cotidiana de las abejas. ${ }^{34}$

El pensamiento y su expresión a través del lenguaje ponen en movimiento ese elemento energético por el cual son posibles el intercambio simbólico y el diálogo intersubjetivo. Ese elemento es el que Beuys quiere agregar al marxis-

32. Véase Jürgen Habermas, Problemas de legitimación en el capitalismo tardio (Buenos Aires: Amorrortu, 1995).

33. Habermas, Problemas de legitimación, 4I.

34. Götz, Konnertz et al., Joseph Beuys, 4I. 


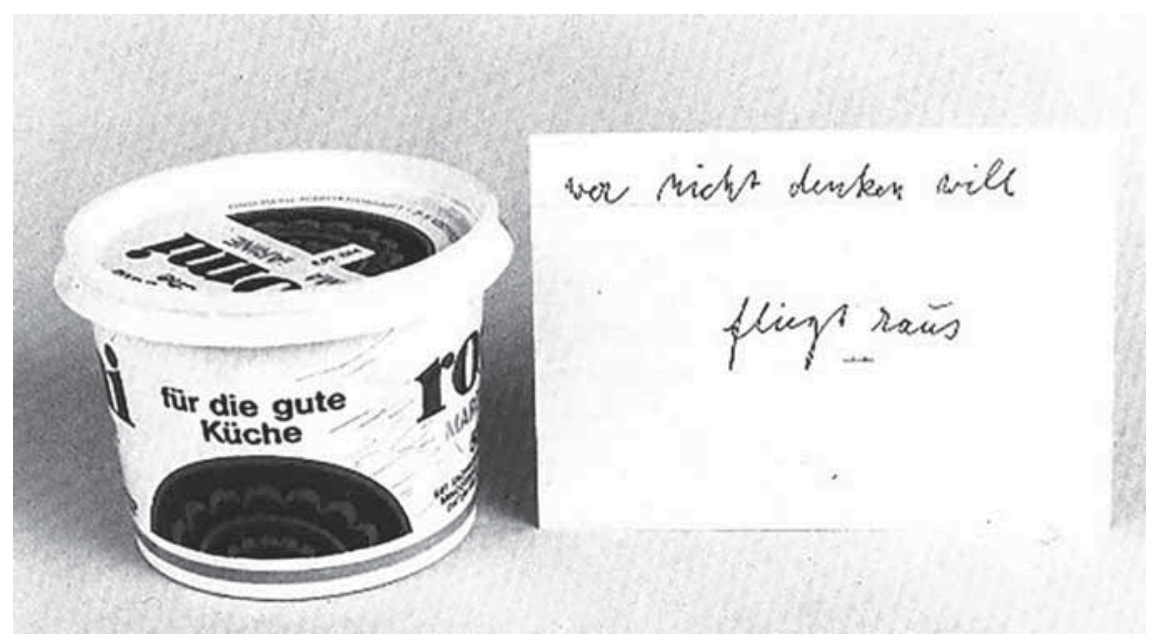

3. Joseph Beuys, Wirtschaftswerte, Apollo (Valores económicos, Apollo), 1977, tomada de Joseph Beuys. The Multiples. Catalogue Raisonné of Multiples and Prints (Cambridge: Busch-Reisinger Museum/Harvard University Art Musseum, 1997). D. R. (C) Joseph Beuys/ BILDKUNST/SOMAAP/México/2oI3.

mo. Así, la Fettecke (Esquina de grasa) (fig. 4) y la Honigpumpe am Arbeitsplatz (Bomba de miel en el lugar de trabajo) (1977) (fig. 5) significan, afirma el artista, que la acción del calor "es la verdadera política, la alternativa al marxismo". 35 En otras palabras, en la medida en que la producción de sentido es una tarea selectiva y social, lo que le hace falta al marxismo es una concepción del pensamiento, el lenguaje y los procesos de la comunicación que asuma su dimensión afectiva. La comunicación y la creatividad impulsan las relaciones entre los seres humanos y constituyen la condición previa al cuidado, preservación y crecimiento de la vida en sentido general; son, por tanto, "la sustancia" común a los procesos espirituales y biológicos. Beuys brinda dos ejemplos: la bomba atómica que "nos muestra hasta dónde pueden llegar el pensamiento y la creatividad en el ámbito de una ciencia materialista y positivista", es decir, en una ciencia carente del elemento espiritual porque la bomba "es improductiva, no produce amor", y la política, que, como lo atestigua la

35. Joseph Beuys y Volker Harlan, Qu'est-ce que l'art? (París: L'Arche, I992), 43; Volker Harlan, Was ist Kunst. Werkstattgespräch mit Beuys (Stuttgart: Urachhaus, 1986). 


\title{
I I 4
}

\author{
BLANCA GUTIÉRREZ GALINDO
}

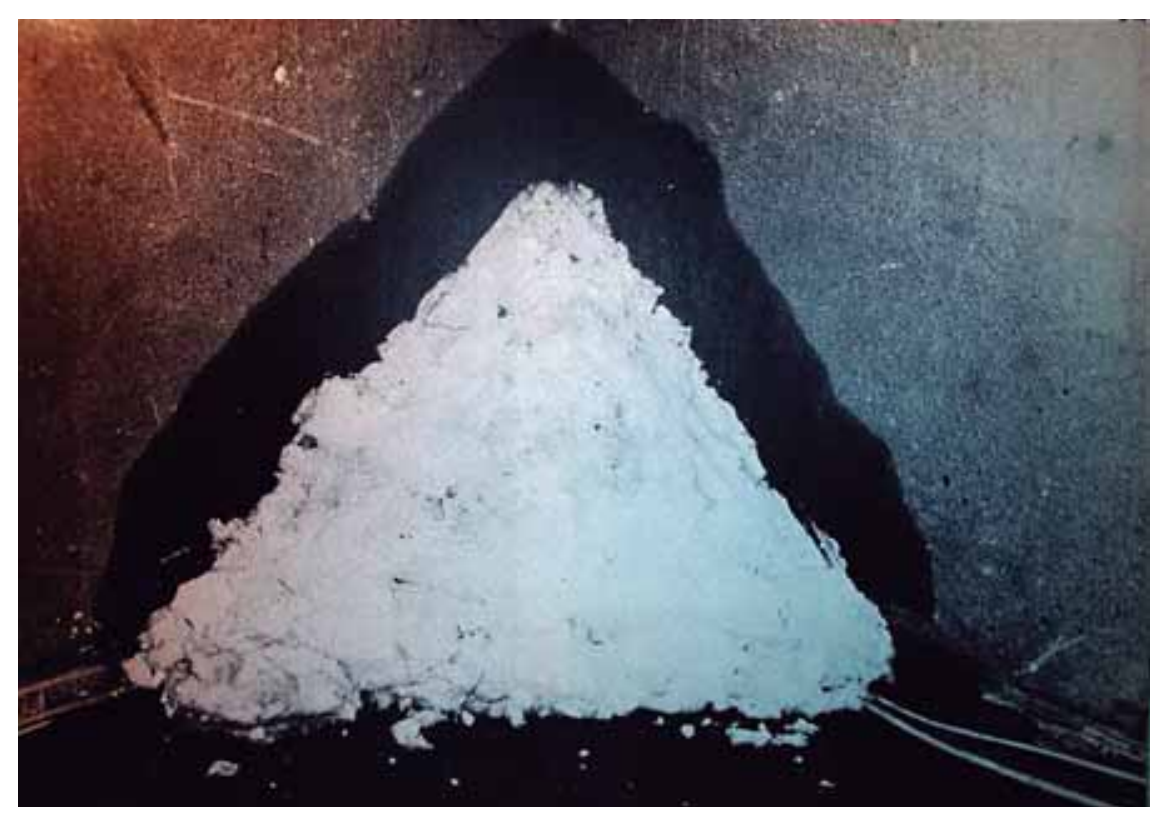

4. Joseph Beuys, Fettecke (Esquina de grasa), 1960, tomada de http://btva.uni-lueneburg.de/ Beuys/project_de/content/card/frames/b_fetteckeo_m2.htm, consultado el 3 de septiembre de 20I3. D. R. () Joseph Beuys/Bildkunst/somaap/México/20I3.

experiencia de los Verdes, carece también de amor porque ser "políticamente activo supone reubicar a todo potencial de ideas de futuro". ${ }^{6}$

Para Beuys, ser "políticamente activo" quiere decir imaginar creativamente el futuro y esto sólo es posible en relación con los otros. Así pues, a la definición materialista del trabajo explicada por Marx como "la actividad racional encaminada a la producción de valores de uso, la asimilación de las materias naturales al servicio de las necesidades humanas, la condición general del intercambio de materias entre la naturaleza y el hombre, la condición natural eterna de la vida humana, y por tanto, independiente de las formas

36. Beuys, "Discurso sobre el propio país", en Joseph Beuys, ed. Klüser, 207. Para 1985 el Partido Verde había dejado de ser "el brazo político electoral" de los movimientos sociales y mostraba signos de entrar en lo que Claus Offe llamó una "simple socialdemocratización de los Verdes". Un análisis de las etapas del Partido Verde se encuentra en Claus Offe, "Entre movimiento y partido. ¿Los verdes en la 'crisis de adolescencia' política?", en Partidos políticos $y$ movimientos sociales (Madrid: Sistema, I996), 245-265. 


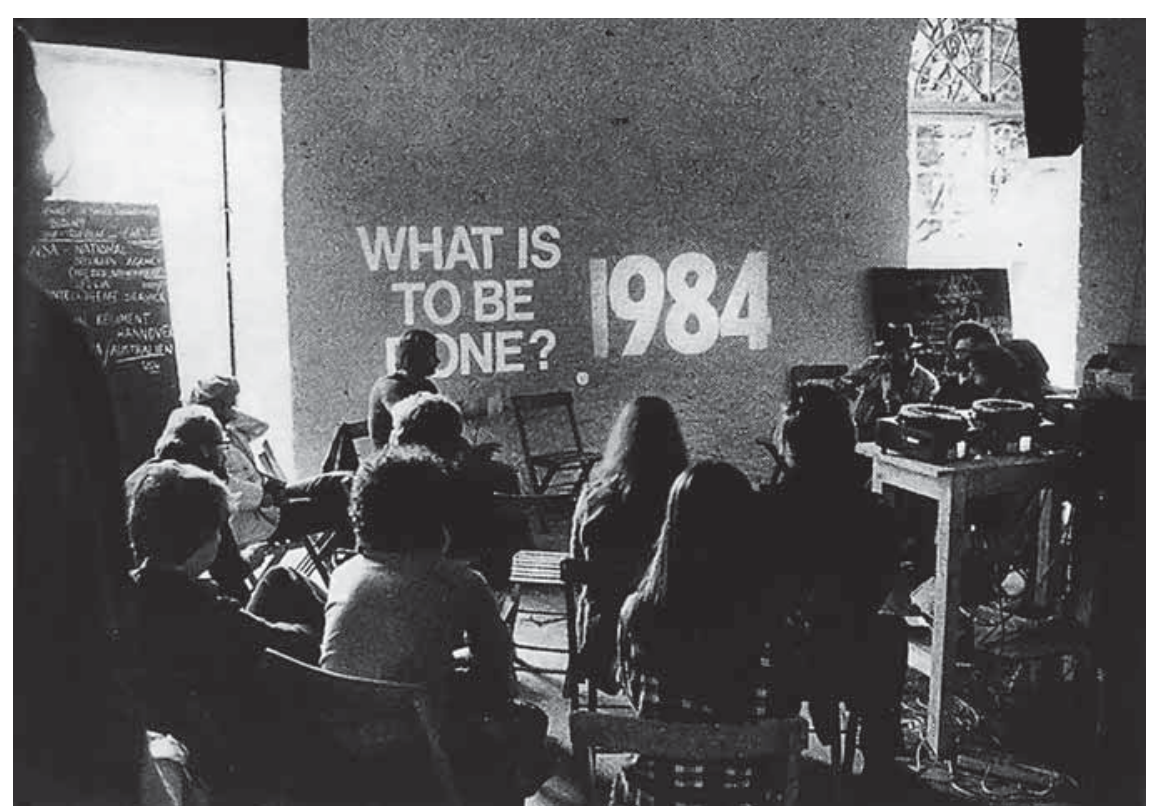

5. Joseph Beuys, Honigpumpe am Arbeitsplatz (Bomba de miel en el lugar de trabajo), Kassel, Documenta, núm. 6 (1977). D. R. (C) Joseph Beuys/Bildkunst/somaAp/México/20I3.

y modalidades de esta vida y común a todas las formas sociales por igual", 37 Beuys agrega la dimensión afectiva que constituye la base de la creatividad humana y dota de sentido a la voluntad más allá de los fines individuales. Esta dimensión afectiva o energético-vital es necesaria a la fertilización de todas las esferas de la existencia y constituye la condición necesaria para el actuar de los seres humanos como agentes sociales, o dicho en los términos de Beuys, "como agentes evolutivos".

Ahora bien, Marx define el producto del trabajo como "un valor de uso, una materia dispuesta por la naturaleza y adaptada a las necesidades humanas mediante un cambio de forma". ${ }^{38} \mathrm{El}$ del trabajo es, así, un proceso dinámico transformador que supone al trabajo anterior borrado en cada nuevo proceso y de esta manera el trabajo vivo incluye al trabajo muerto convirtiéndolo en medio de producción. Así, por ejemplo, las máquinas que han dejado de ser

37. Marx, El capital, I36.

38. Marx, El capital, I33. 


\section{I 6}

BLANCA GUTIÉRREZ GALINDO

utilizadas también se ven sometidas "a la acción destructora del intercambio natural de materias. El hierro se oxida, la madera se pudre. La hebra no tejida o devanada es algodón echado a perder. El trabajo vivo tiene que hacerse cargo de estas cosas, resucitarlas de entre los muertos, convertirlas de valores de uso potenciales en valores de uso reales y activos". ${ }^{39}$

En este sentido, el trabajo es un proceso de transformación constante, un encadenamiento perpetuo de cambios de estado que supone una continuidad histórica, así como la naturaleza supone la de sus ciclos biológicos. Como para Marx, para Beuys el trabajo es un proceso energético impulsor de "la resurrección" incesante de lo humano y la naturaleza, donde lo vivo alimenta a lo muerto insuflándole nueva vida. ${ }^{40}$ Este proceso energético es, así descrito por Marx, un proceso erótico en tanto proceso de regeneración y fertilización. Beuys extiende este principio erótico al conjunto de las actividades humanas y lo sitúa más allá de la idea de productividad. ${ }^{4}$ Quizá por esa razón y usando el Sagrado Corazón de Jesús (Sacro Cuore di Gesu) como símbolo de amor por la humanidad, en I97I escribió sobre cinco imágenes idénticas las frases siguientes: "El inventor de la máquina de vapor" (Der Erfinder der Dampfmaschine); "El inventor de la electricidad" (Der Erfinder der Elektrizität); "El inventor de la tercera ley de la termodinámica" (Der Erfinder des 3. Thermodynamischen Hauptsatzes); ${ }^{22}$ "El inventor de la constante de gravitación uni-

39. Marx, El capital, I35.

40. Esta idea articula también la de Alexander Kluge sobre el poder de los sentimientos. Véase por ejemplo la película El poder de los sentimientos (Die Macht der Gefühle), realizada en I983. A diferencia de lo que ocurre en general en las películas, en ésta se trata de revivir a un muerto.

4I. Desde esta perspectiva también es posible analizar las ideas de sufrimiento, ascetismo y misión que con frecuencia se asocia a la figura de Beuys. Beuys relacionó la figura de Cristo con el socialismo declarándolo incluso el primer socialista de la historia de la humanidad. El problema del sacrificio y el amor encuentran una explicación muy completa en un discurso de dos horas pronunciado con motivo de la recepción del doctorado honorario que le concedió el Nova Scotia College of Art and Design en 1976: "Joseph Beuys, 1976", en Artists Talk 1969-1977, ed. Peggy Gale (Halifax: The Press of the Nova Scotia College of Art and Design, 2004). Los temas de la obra de Beuys relacionados con el cristianismo se encuentran desarrollados también en Friedheim Mennekes, Joseph Beuys. Christus DENKEN-PENSAR Cristo (Barcelona: Herder, 1977). No está de más hacer notar que la implicación masiva de los cristianos - la mayoría pertenecientes a la Iglesia evangélica, pero también una importante minoría católica - se convertirá en un rasgo distintivo de los movimientos sociales alemanes durante los años ochenta.

42. En este aspecto tenemos una diferencia fundamental entre Beuys y el pensamiento marxiano. Al concepto de trabajo explicado como un proceso inagotable cuya fuerza reside 
versal” (Der Erfinder der Gravitationskonstante), y "El inventor de la síntesis del nitrógeno" (Der Erfinder der Stickstoffsynthese). ${ }^{43}$

El trabajo es, pues, la premisa fundamental de lo que Beuys llamó "antropología de la creatividad". Para él, el arte es trabajo animado por la energía erótica, es práctica productiva ligada a la dimensión biológica del cuerpo; tiene su origen en el pensamiento, es animado por el sentimiento y constituye la expresión de la voluntad creadora. El trabajo es la actividad que permite producir, fertilizar y regenerar constantemente el mundo y a los seres humanos. Pero bajo la organización productiva capitalista, el trabajo se encuentra reducido a potencial puramente biológico como fuerza de trabajo (Arbeitskraft), es decir, está inscrito en una relación de puro intercambio mercantil, de manera que, como explica Marx, en el trabajo no se valoriza el ser humano y su vida, sus capacidades, sino el dinero como capital:

en el flujo constante de energías, subyace la idea moderna de proceso. Esta idea, que se estableció como paradigma para la biología, la geología y la economía en el siglo xix, supone también las ideas de desarrollo y evolución, las cuales fueron incorporadas por Marx y Engels a partir de su aceptación de la teoría de la evolución darwiniana y del primer principio de la termodinámica (ley de la conservación de la materia y la energía). Marx y Engels veían en la teoría de Darwin el fundamento histórico-natural de su propia concepción social, lo cual debió haber fascinado al Beuys estudioso de las ciencias naturales en la lectura de, por ejemplo, los Manuscritos económico-filosóficos de 1844, donde el joven Marx afirmó: "Algún día la ciencia natural se incorporará a la ciencia del hombre, del mismo modo que la ciencia del hombre se incorporará a la ciencia natural, habrá una sola ciencia”. No obstante, si bien los fundadores del marxismo aceptaron el primer principio de la termodinámica —el cual señalaba a la energía como el factor cuantificable común a todos los fenómenos del mundo físico por lo que reforzaba indirectamente su concepción del mundo económico, en la que el trabajo, en general, era una sustancia común subyacente tras el velo monetario que recubre los intercambios—-, rechazaban el segundo principio según el cual la entropía del universo o de una estructura dada aumenta constantemente y de forma irrevocable. Con ello rechazaban la posibilidad de fundamentar la teoría del valor/trabajo en términos energéticos. Esta idea había sido elaborada por el fisiólogo ucraniano Serchii Podolinsky, quien buscaba construir una teoría de las necesidades basada en los conocimientos modernos de las ciencias físicas. Véanse Miguel Cuerdo Mier y José Luis Ramos Gorostiza, Economía y naturaleza, una historia de las ideas (Madrid: Síntesis, 2000), 82-87, n. 4, y Joaquín Valdivieso, “"El ser natural humano.' Ecologismo, marxismo, humanismo", en La izquierda verde, ed. Ángel Valencia Saíz (Barcelona: Icaria, 2006), 50-5I.

43. Estas imágenes también han sido interpretadas desde la perspectiva de la antroposofía de Rudolf Steiner, quien no solamente sostuvo la existencia histórica de Cristo, sino también interpretó su figura como un punto de inflexión en los procesos evolutivos de la Tierra y de la historia. 
Al transformar el dinero en mercancías, que luego han de servir de materias para formar un nuevo producto o de factores de un proceso de trabajo; al incorporar a la materialidad muerta de estos factores la fuerza de trabajo viva, el capitalista transforma el valor, el trabajo pretérito, materializado, muerto, en capital, en valor que se valoriza a si mismo, en una especie de monstruo animado que rompe a "trabajar" como si encerrase un alma en su cuerpo. ${ }^{44}$

Esta "especie de monstruo animado" es el dragón al cual Beuys llama a combatir al principio del "Discurso sobre el propio país". Este monstruo es el que, en efecto, consume la energía invertida por el obrero en el trabajo como pura fuerza de trabajo reprimiendo su potencial creativo. En otros términos, el capital se valoriza a sí mismo sacrificando las capacidades humanas porque su existencia y reproducción dependen del desarrollo unilateral de los poderes del pensamiento y de la exclusión de los otros poderes creativos del mundo de la naturaleza y del mundo humano. ${ }^{45}$ De ahí la idea de Beuys de que "el dinero no es un valor económico", sino que las capacidades son el verdadero patrimonio, el verdadero capital de la humanidad. ${ }^{46}$

Así pues, las capacidades creativas, constructivo-eróticas, son el auténtico valor económico, de manera que, dice Beuys, la fórmula del concepto expandido de arte es "ARTE=CAPITAL". 47 Por ello, el concepto de trabajo como fundamento de "la antropología de la creatividad" es, también, la base de una "economía de las capacidades". De ese modo el proyecto beuysiano ambiciona la liberación del potencial creativo del trabajo de su sometimiento a las condiciones de alienación impuestas por la modernidad capitalista $-\mathrm{y}$ comunista. Esta ambición se extiende más allá de las actividades remuneradas para comprender, por ejemplo, el trabajo doméstico del ama de casa que "rinde un servicio al conjunto social" porque tiene un carácter "universal" en cuanto "se ocupa de la crianza"48 y de todas aquellas actividades orientadas a la conti-

44. Marx, El capital, I46.

45. Lucrezia de Domizio Durini explica esta idea como parte de la crítica beuysiana al materialismo, no al capitalismo. Cf. The Felt Hat. Joseph Beuys. A Life Told (Milán: Charta, I997), 86. Véase también "Economía/vida económica", en Joseph Beuys (Madrid: Museo Nacional de Arte Reina Sofía, 1994), 26r.

46. Al respecto véase Adolfo Sánchez Vázquez, "Producción material y producción artística”, en Las ideas estéticas de Marx (México: Siglo XXI, 2005).

47. Beuys, "Discurso sobre el propio país", en Joseph Beuys, ed. Klüser, 208.

48. Bodenmann-Ritter, Joseph Beuys, 35. 
nuidad de los procesos biológicos humano-sociales: "El valor económico es la capacidad que el hombre invierte en el trabajo, es el producto que crea en su lugar de trabajo, ya sea una buena escultura, un cuadro admirable, un coche que no contamina el medio ambiente, una patata sana y buena, un pescado sano que el pescador extrae del mar, y no otro envenenado, lo que hace que comamos muy poco pescado porque podríamos morir". 49

Aquí Beuys se refiere a la dimensión práctico-moral del trabajo que reside en el sentido social y moral del mismo. El fin del trabajo es instrumental, se refiere a la subsistencia, pero, como pensó el joven Marcuse, la subsistencia en el mundo humano es existencia y en cuanto tal ocurre en un espacio conformado por otros, de manera que posee un sentido moral como medio de solidaridad y de creación de vínculos sociales, los cuales Beuys concibe como anclados en el cuidado de la vida. El trabajo es fundamental para la vida individual a la vez que para la esfera pública, porque es el eje de la cohesión social en "el sentido de que se hace a sí mismo funcional dentro del campo de la comunicación y la colaboración". 50

En la concepción de Marx está presente esta dimensión y lo está de manera radical en tanto a través del trabajo el hombre es capaz de género, es decir, que "para el hombre hay un continente original, un principio que hace que los individuos no sean extrańos unos de otros, sino que sean precisamente humanos, en el sentido de que en cada hombre está presente y necesariamente el género entero". .' Marx no entiende la palabra género (Gattung) como especie natural, sino como el principio original "que en cada individuo y en cada acto funda al hombre como ser humano y, al fundarlo así, lo con-tiene, lo mantiene unido a otros hombres, haciendo de él un ser universal". 52 Por ello, al arrancarle al hombre el objeto de su producción, el trabajo alienado le arranca también su "vida de género, su efectiva objetividad genérica (Gattungsgegenständlichkeit)".53

La redefinición beuysiana del arte se refiere también a la dimensión estético-expresiva del trabajo lo cual implica, como ya se señaló, que en la acción creativa el hombre se produce a sí mismo como ser social-histórico. La autorrealización personal es social en la medida en que pone al hombre en

49. Beuys, "Discurso sobre el propio país", en Joseph Beuys, ed. Klüser 2 II.

50. De Domizio Durini, The Felt Hat, 97.

51. Agamben, El hombre sin contenido, I32.

52. Agamben, El hombre sin contenido, I33.

53. Agamben, El hombre sin contenido, I3O. 
relación con otros seres humanos y con la naturaleza a través de su capacidad de crear, de ampliar las posibilidades del mundo mediante el proceso incesante de regeneración y resurrección de lo muerto, en este caso las capacidades liquidadas, cercenadas o reprimidas por el proceso de valorización del capital a partir de las cuales han ocurrido los procesos modernizadores.

\section{Arte ampliado}

No sorprende, entonces, que la teoría plástica de Beuys se inscriba en aquella tradición donde las abejas y la colmena son las metáforas de una sociedad laboriosa, solidaria y perfecta, la cual desde la antigua Grecia ha cautivado los imaginarios artístico y político. Aunque el prestigio de las abejas se remonta a la Antigüedad, fue durante la modernidad cuando su organización, basada en el trabajo, habría de convertirse en modelo de virtud social y perfección económica y política. La abeja obrera, disciplinada y solidaria, y la abeja arquitecta, constructora de colmenas, se convirtieron en símbolos de perfección social y productiva y el trabajo se ubicó, como señalamos anteriormente, en valor central y denominador común de cualquier actividad humana. No es extrańo, por tanto, que la colmena fuera ubicada como el modelo social al cual aspiraban proyectos de la más diversa índole ideológica, cuya ambición fue corregir el rumbo de la modernidad. ${ }^{4}$ Tampoco que el mundo apícola gozara de la atención de autores como Kant y Marx.

La idea de un arte ampliado se articula, por tanto, en torno a las dimensiones práctico-moral y estético-expresiva del trabajo. "Remontar la alienación en el mundo del trabajo" (die Entfremdung in der Arbeitswelt überwinden) - meta de la ampliación del arte y del proyecto de la plástica social— supone el principio de la fraternidad según el cual cada uno trabaja para la complacencia de las necesidades de otros, no solamente para la satisfacción de las propias.5 Para Beuys, el arte es actividad productiva en la misma medida en que lo es el trabajo o toda actividad práctica consciente. En la sociedad

54. En La metáfora de la colmena. De Gaudi a Le Corbusier (Madrid: Siruela, I998), Juan Antonio Ramírez explora las innovaciones formales, concepciones y discursos artísticos relacionados con el mundo apícola.

55. Véase "Gespräch zwischen J. Beuys, B. Blume und H.G. Prager vom I5.I I.I975", en Documenta 6, Malerei, Plastik, Performance (Cassel: Paul Dierichs, Verlag und Gesamtherstellung, I977), disco I, I57. 
organizada a partir del trabajo alienado, el arte se ha convertido en el espacio donde se resguarda la energía erótica necesaria para "resucitar" el cuerpo social conduciéndolo a "una nueva forma”. En su condición moderna, es decir, autónoma, el arte contiene y aísla esa energía creadora que funda al ser humano y a la sociedad privatizando lo que para Beuys es un bien común: "Toda capacidad procede de la capacidad artística del ser humano, es decir, de ser activo creativamente". ${ }^{6} \mathrm{El}$ arte es "la palanca" "no [...] agotada", proveniente "de un lejano pasado histórico", que no obstante "vuelve como futuro, como futuro total, el del hombre que se hace consciente".57 Así, el arte es "el más grande depósito de energía revolucionaria”, pero como práctica especializada se encuentra él mismo alienado y "ha hecho caer en la soledad a la inmensa mayoría de los seres humanos". ${ }^{8}$

Así pues, la liberación del arte y la del trabajo se suponen en una relación de necesidad. A semejanza de los artistas de los movimientos de vanguardia, Beuys intentó liberar aquella energía que, emancipada de su confinamiento en la institución del arte, podría fundar la praxis vital sobre una lógica diversa a la ordenada por los procesos de valorización del capital. 59 En este proyecto de ampliación del arte se inscribe la ambición de configurar un nuevo orden social y humano a partir de un concepto de economía liberado de la lógica de la propiedad privada, la división del trabajo y los principios de la acumulación y el consumo, que en los países con economía de mercado es dominio de los empresarios privados y en el comunismo del Estado.

56. Bodenmann-Ritter, Joseph Beuys, 7I.

57. Beuys, "Discurso sobre el propio país", en Joseph Beuys, ed. Klüser, 206.

58. Beuys, "Discurso sobre el propio país”, en Joseph Beuys, ed. Klüser, 202. Resulta curioso que haya sido esto lo que Rudolf Steiner reprochó al "sistema ideológico de Karl Marx". Véase El nuevo orden social, www.emagister.com, 35.

59. Según Thierry de Duve, una gran parte del arte moderno y sus utopías - lo mismo las comprometidas con un mesianismo de carácter religioso, que político o cultural-, han exigido corregir el mal hecho al proletario y han demandado que el hombre en general, el hombre como perteneciente al género, sea "liberado" y "desalienado". Además afirma que subjetivamente el artista moderno es el proletario por excelencia porque el régimen de la propiedad privada lo fuerza a depositar en el mercado del arte las cosas que serán tratadas como mercancías, pero, de poseer algún valor estético, esas creaciones deben ser producciones y concreciones de su fuerza de trabajo y, de ser posible, de ninguna otra cosa. La concepción burguesa del arte, continúa De Duve, con una mano "reifica" la obra y con la otra la juzga (estéticamente) para que manifieste la facultad de producirvalor, la cual por ser auténtica, debe ser única y prometer valor para todos y por tanto tener su asiento en la naturaleza misma del artista como individuo humano en general. De Duve, "Joseph Beuys ou le dernier des prolétaires", I8. 
El logro de esta meta constituiría una liberación radical de la imaginación humana hacia todas las esferas de la existencia cotidiana. Ello abriría el paso a una economía fundada sobre el principio de las capacidades humanas. Por eso, al principio del "Discurso sobre el propio país: Alemania” Beuys no hace un llamamiento a batirse contra el capitalismo, sino contra el concepto de capital que organiza la economía capitalista como lo hizo, en su momento, la comunista. Se trata, entonces, de crear un nuevo concepto de capital, de "revolucionar el concepto", es decir, en principio, de poner en movimiento el pensamiento para imaginar alternativas y, por esa vía, prefigurar una nueva organización económica en tanto "obra de arte social del futuro". ${ }^{60}$ Esta obra

6o. A lo largo de su discurso, Beuys recurre a la retórica de la "obra de arte total" o Gesamtkunstwerk, un concepto atribuido a Richard Wagner. Según diversos autores, Wagner utilizó escasamente en sus escritos el término Gesamtkunstwerk para designar lo que conocemos como "obra de arte total"; más bien se refirió a das Kunstwerk der Zukunft "la obra de arte del futuro", que connota mucho menos la idea de "total" o "absoluta" y mucho más la idea de "en común". Denis Blabet señala que Wagner se vale de una serie de equivalentes tales como höchste gemeinsames Kunstwerk, "la obra de arte más común"; allgemeinheitliches Kunstwerk, "la obra de arte más general", y allgemein verstänliches Kunstwerk, "la obra de arte más total e inteligible". Por tanto, afirma, quizá deberíamos entender por Gesamtkunstwerk "obra de arte integral" o, mejor, "obra de arte en común". Según Blabet, las palabras zusammen e insgesamt, bases etimológicas del término, dan la idea de "conjunto", de "vocación unitaria" y de ninguna manera de totalidad ni homogeneidad, mucho menos la de "coincidencia de las artes". Véase "L'Oeuvre d'art totale et Richard Wagner", en L'Oeuvre d'art total, ed. Konigson, 2r. Lo mismo señala Eric Michaud en su artículo "Oeuvre d'Art total et totalitarisme", en Jean Galard, Julián Zugazagoitia et al., L'Oeuvre d'art total (París: Gallimard, 2003), 36. En Das Kunstwerk der Zukunft (La obra de arte del futuro), publicada en I850 durante su exilio en Zúrich, Wagner denuncia que "desde la perspectiva de la vida pública" el arte no es otra cosa sino lujo y superficialidad, un pasatiempo de autodiversión para unos cuantos. Indiferente a la naturaleza de los sentidos e insensible a las necesidades de la comunidad, este arte debe ser superado en una forma de arte capaz de ir más allá de la red de intereses utilitarios en los que se encuentra para restituirlo a su naturaleza artística originaria. La "obra de arte común" nace de la coexistencia de diversas artes: danza, música, poesía, arquitectura, escultura y pintura, conservando cada una sus características de manera que sus fuerzas específicas puedan asegurar su poder común para engendrar un arte trascendente. Al postular la integración de las artes, Wagner supuso su origen común en el impulso creativo. Los límites entre las artes son puramente materiales y deben desaparecer para dar lugar al arte mismo, al arte común, universal e ilimitado. Así pues, la "obra de arte común" está inscrita en las potencialidades de cada una para operar su propia trascendencia en una síntesis superior. La Gesamtkunstwerk debe ser una obra orgánicamente unida no sólo por las artes, sino también porque superará el individualismo de los artistas y éstos se unirán espontánea y momentáneamente para dar lugar a la obra, una reunión que "no ha existido jamás y que no deberá jamás repetirse". La 
sería, según Beuys, la realización de todos y cada uno de los seres humanos, es decir, una construcción social producto de la acción libre y democrática de todos sus miembros.

La realización de este nuevo orden social, de esta "obra social del futuro", supone una reorganización económica total donde "Nadie compra y nadie vende capacidades y trabajo" y por ello es necesario salvar el trabajo de la red mercantil en la cual lo inscribe el capitalismo para restituirle su valor de uso, es decir, es preciso situarlo en el interior de una redefinición del sistema de las necesidades materiales y espirituales: "Elaborar y conseguir los productos que necesitamos es hoy posible. [...] no tenemos necesidad de comprar lo que nos impone comprar un capitalismo ávido de beneficio. Aquello que no necesitamos bien que lo sabemos. Hemos de evitar aquello que nos impida conocernos. Tendremos leyes económicas que nos aclaren la función del dinero, pues la liberación del dinero es la condición de la liberación del trabajo". ${ }^{61}$

La transformación del concepto de capital y la construcción de una nueva economía, una basada en la desdiferenciación entre arte y trabajo — lo cual supondría, precisamente, la superación (Aufhebung) de la condición moderna del arte-, es una tarea que Beuys considera urgente si en verdad se pretende frenar las tendencias destructivas del capitalismo; sólo de esa manera, de-

obra de arte total es, así, el acto artístico soberano que abandona a sus creadores para asumir una existencia propia e inmediata donde ella y el artista encuentran su plena realización en su completa absorción dentro del público. Para Wagner, el artista del futuro será el pueblo integrado en la comunidad unida fraternalmente por el comunismo que hará posible la unión de las artes, de los artistas y de la obra con el público, o mejor, su desaparición en la experiencia estética. Fragmentos de los textos de Wagner traducidos al inglés se incluyen en Charles Harrison, Paul Wood et al., Art in Theory I8I5-1900. An Anthology of Changing Ideas (Malden, Massachusetts: Blackwell, I998) 47I-478. Otros artistas interesados en la ampliación del arte usaron expresiones como "arte total", "danza total”, "hombre total” o incluso "obra de arte total", de Allan Karpow a los artistas fluxus y Ben. Véanse por ejemplo los textos de Allan Karpow, "Notes on the Creation of a Total Art", en Essay on the Blurring of Art and Life (Los Ángeles: University of California Press, I993), IO-I4, y Jean-Clarence Lambert, Arte total. Selección de textos de imágenes de la revista Opus International (México: Era, 1974). Sobre la idea de sinestesia presente en la de arte total y su destino en la industria cultural, específicamente en el cine, se puede ver el extraordinario artículo de Marcella Lista, "Des correspondences au Mickey Mouse Effect: l'ouvre d'art totale et le cinema d'animation", en Galard y Zugazagoitia, L'Oeuvre d'art total, I09-I38. Sobre la relación entre obra de arte total y nacionalsocialismo véase Philippe Lacoue-Labarthe y Jean-Luc Nancy, El mito nazi (Madrid: Anthropos, 2002).

6I. Beuys, "Discurso sobre el propio país", en Joseph Beuys, ed. Klüser, 208. 
claró, es posible impedir una tercera guerra mundial: "Las causas de las dos guerras mundiales residen en la esclavización del espíritu por parte del Estado y la economía capitalista". Coincide, así, con el marxismo crítico en señalar que las guerras mundiales, el fascismo y los estados totalitarios, y, en fin, la aparición y puesta en marcha de las fuerzas destructivas del capitalismo, son consecuencia del proceso civilizatorio fundado en la instrumentalización y alienación de las potencialidades humanas.

\section{Arte y democracia}

El trabajo no es solamente la actividad que define al hombre como perteneciente al género humano y la pieza fundamental de la valorización del capital; es, también, el polo opuesto del arte en su definición moderna. En efecto, aunque el arte es considerado en la modernidad bajo los parámetros de lo que en párrafos anteriores explicamos como práctica productora, como praxis, su autonomía se explica y organiza también a partir de su diferenciación con el trabajo social. Ya en la Crítica del juicio Kant se propuso vertebrar las condiciones a priori que fijan las fronteras de lo estético respecto de otras formas de experiencia humana. Se trataba de fundar la estética de modo trascendental a partir de la crítica de las condiciones formales de la experiencia singular del juicio estético. Desde esta perspectiva, Kant estableció la condición de posibilidad del arte precisamente por oposición con los procesos del trabajo, enunciando las características que éste adquiere en la moderna sociedad capitalista como "trabajo enajenado", como "trabajo doloroso" dependiente de la voluntad de otros y ligado a la producción de riquezas. En otras palabras, en la tercera crítica encontramos enunciadas las premisas de la experiencia moderna del trabajo y las de la definición moderna del arte en tanto esfera autónoma singularizada por sus modos de experiencia y utilidad, y encontramos también, y no menos importante, la tentativa de ubicar la esfera del arte como mediador entre la esfera del conocimiento (entendimiento) y la facultad de desear o razón práctica orientada a la noción de libertad, es decir, como mediadora entre ciencia y moralidad. Esta tentativa resultará fundamental para el proyecto estético romántico, ${ }^{62} \mathrm{y}$, como hemos venido indicando, re-

62. Pensadores como Schelling, Schiller y Goethe tomaron de la tercera critica de Kant la idea de la teleología con la cual lograron poner en cuestión la autonomía de las esferas de la 
viste especial importancia para completar el proyecto beuysiano en la medida en que el concepto de arte ampliado abre la posibilidad de direccionar el arte hacia el proyecto de la plástica social.

\section{Arte}

Según Kant, "Arte se distingue de naturaleza, como hacer (facere) de obrar o producir en general (agere), y el producto o consecuencia del primero como obra (opus), de la segunda como efecto (effectus). Establece, por tanto, que:

Según derecho debiera llamarse arte sólo a la producción por medio de la libertad, es decir, mediante una voluntad que pone razón a la base de su actividad, pues aunque se gusta de llamar al producto de las abejas (los panales construidos con regularidad) obra de arte, ocurre esto sólo por analogía con este último; pero tan pronto como se adquiere la convicción de que no fundan aquellas su trabajo en una reflexión propia de la razón, se dice enseguida que es un producto de su naturaleza (del instinto), y sólo a su creador se le atribuye como arte. ${ }^{63}$

De acuerdo con lo expuesto hasta aquí, Marx coincide con Kant en lo referente a la diferencia entre labor y trabajo, que éste último ejemplifica también con la actividad apícola. Los productos de la naturaleza, como los panales y la miel, aunque también poseen "causa productora", no son arte en la medida en que carecen de una causa productora "capaz de pensar un fin", al cual las cosas, como un pedazo de madera tallada, "deben su forma”. ${ }^{64}$ Así, al referirse a la actividad de las abejas como ejemplo contrario del trabajo libre, señala que por libertad entiende actividad intencional, deliberada, voluntaria. Vea-

cultura. Robert J. Richards ha señalado que los llamados biólogos románticos entendieron la naturaleza como un depósito no únicamente de regularidades legales y deleites estéticos, sino también, e igualmente, de valores morales. The Romantic Conception of Life (Chicago: The University of Chicago, 2002). Sobre las relaciones entre Beuys y el romanticismo alemán véanse por ejemplo: Cecilia Liveriero Lavelli, Joseph Beuys e le radici romantiche della sua opera (Bolonia: Clueb, I995); Max Reithmann, Joseph Beuys. La mort me tient en éveil (Tolosa: ARPAP, 1994); Theodora Vischer, "Beuys and the Romanticism", en Joseph Beuys. The Reader, eds. Claudia Mesch y Viola Michely (Cambridge: The mit Press, 2008), I5 I-I69.

63. Immanuel Kant, Crítica del juicio (México: Porrúa, 2003), 340, 43.

64. Kant, Critica del juicio, 340, 43. 
mos ahora la diferencia entre arte y oficio, o entre arte y trabajo, al que Kant también llama "arte mercenario": "Consideran al primero [al arte] como si no pudiera alcanzar su finalidad (realizarse), más que como juego, es decir como ocupación que es en sí misma agradable, y al segundo [el arte mercenario] considérasele de tal modo que, como trabajo, es decir, ocupación que en sí misma es desagradable (fatigosa) y que sólo es atractiva por su efecto $(v$. gr., la ganancia) y puede ser impuesta por la fuerza" ${ }^{65}$

Kant ubica así el arte y el trabajo en los polos opuestos de la libertad y la necesidad, del juego y el trabajo, del agrado y el desagrado, y establece una jerarquía en la cual el estadio más elemental es la actividad de las abejas, que sólo produce un efecto; le sigue el del trabajo "desagradable" y "fatigoso", como ocupación "impuesta por la fuerza”, y finalmente la producción "por medio de la libertad", es decir, "mediante una voluntad que pone razón a la base de su actividad". Así, mientras en el trabajo doloroso lo que se realiza es la voluntad de otro, para el artista es posible la conciencia de sí y de los propios fines.

Pero si el arte se diferencia de la actividad de las abejas por su finalidad, para causar placer debe, no obstante, "parecer" producto de la naturaleza. "En un producto del arte bello hay que tomar conciencia de que es arte y no naturaleza; sin embargo, la finalidad en la forma del mismo debe parecer tan libre de toda violencia de reglas caprichosas como si fuera un producto de la mera naturaleza." ${ }^{6} 6$ Y esto es posible porque el arte es producto del genio, que Kant definió como "una capacidad espiritual innata (ingenium) mediante la cual la naturaleza da la regla al arte" ${ }^{67}$ "Como naturaleza, escribe Kant, aparece un producto del arte, con tal de que se haya alcanzado toda la precisión en la aplicación de las reglas, según las cuales sólo el producto puede llegar a ser lo que debe ser, pero sin esfuerzo, sin que la forma de la escuela sea transparente, sin mostrar una señal de que las reglas las ha tenido el artista ante sus ojos y han puesto cadenas a las facultades del espíritu". ${ }^{6}$

Los resultados de la actividad artística se basan en ese "como si" que hace que veamos el arte como producto de la naturaleza, cuando en realidad es un producto del trabajo. "Genio" es el dispositivo del cual se sirve Kant para operar la mediación entre naturaleza y arte, o entre la obra de arte (opus) producto

65. Kant, Critica del juicio, 34I.

66. Kant, Critica del juicio, 343, 9 45.

67. Kant, Crítica del juicio, 344, 96.

68. Kant, Critica del juicio. 
de la voluntad y la naturaleza y sus estructuras autónomas. Por ello, como afirma Peter Bürger, la esfera de las "bellas artes" no está determinada por el filósofo como una esfera de objetos, sino como un modo de representación. ${ }^{69}$ Un modo de representación cuya singularidad reside en poner en juego el gusto en tanto "facultad de juzgar un objeto o una representación mediante una satisfacción o un descontento, sin interés alguno" y donde el "objeto de semejante satisfacción llámase bello" $7^{\circ}$

La esfera del arte resulta, así, autónoma en un doble sentido. En primer lugar las obras, en tanto producto de la actividad del genio, no se encuentran sometidas a regla alguna. En segundo lugar, como el placer producido por la belleza es puramente contemplativo, es decir, originado de la autoconciencia de un principio interior que anima el libre juego de la imaginación y el entendimiento no referido ni al interés cognitivo o intelectual ni al práctico de lo representado, ${ }^{7 \mathrm{I}}$ quien contempla las obras es liberado de todo interés. Es así como la esfera del arte trasciende la esfera de la utilidad y la eficacia que gobierna la producción material con las antiguas funciones mágicas, religiosas, teóricas o políticas del arte. Recordemos que en su relación con los procesos del trabajo, la idea de praxis, que comprende las ideas de techné y ars, incluía en la Antigüedad todas las prácticas productivas orientadas a resolver las necesidades individuales y comunitarias siguiendo ciertas reglas. En el mundo grecolatino, techné y ars comprendían no solamente lo que conocemos como bellas artes, sino también la carpintería, la medicina o la cocina, es decir, el trabajo realizado con las manos, el del homo faber. Despojadas de necesidad y utilidad - y a diferencia de las ciencias modernas en progreso constante-, las artes se convirtieron en instrumentos especializados de un sector de nuestra aprehensión de lo real: la experiencia de lo bello. A su vez, este consumo especializado produjo, como lo señaló Marx, una subjetividad que reclama el gusto por lo bello. El sujeto de esta experiencia estética es el sujeto burgués propietario privado que Kant libera de todo interés estético cuando define el arte como esfera de lo contemplativo.

69. Según Bürger, el concepto de naturaleza aplicado por Kant no tiene el sentido roussoniano de la inmediatez, sino que es la designación de una realización configurada según el ideal del comportamiento de la aristocracia, del hônnet homme. Este ideal aristocrático fue desarrollado a lo largo del absolutismo, que hizo de la ocultación del trabajo condición de la formación de la personalidad. Peter Bürger, Critica de la estética idealista (Madrid: Visor, I983), II4-II5.

70. Kant, Critica del juicio, 258, 95.

7I. Kant, Critica del juicio, 268-269, g I2. 
Desde esta perspectiva, el arte es el lugar de la unidad entre subjetividad y libertad, entre expresión y naturaleza, características del trabajo no alienado, cuya apreciación, según Kant, no es accesible en principio a todos, sino únicamente al hombre ilustrado, "hombre fino (comienzo de la civilización)" ${ }^{72}$ Pero la construcción estética kantiana que habría de conducir posteriormente a una concepción según la cual el arte es expresión de la voluntad creadora del artista condujo también a la afirmación de las posibilidades de su vinculación con la sociedad, tal como lo atestigua la teoría estética de Schiller. Dicho en otros términos, en la medida en que Kant separa el arte de la lógica de la utilidad impuesta por el capitalismo en su proceso de consolidación como modo de producción dominante, la construcción del arte como esfera autónoma puede ser considerada "función social" y posteriormente abrirá también la posibilidad de vincularlo con finalidades sociales. Un asunto medular en las batallas libradas por los artistas vanguardistas y neovanguardistas, que no ha dejado de estar presente hasta la actualidad.

\section{Autogestión}

Beuys se opuso al conjunto de las ideas fundamentales de la estética moderna y afirmó que las obras de Kandinsky, Lehmbruck y Klee han demostrado que en "una vida reglamentada por el trabajo", "sólo los privilegiados que habían tomado parte en los movimientos culturales burgueses eran capaces de comprender ese arte". ${ }^{73}$ La realización de la idea según la cual "cada ser humano es un artista" implica una socialización del arte que deja atrás el juicio estético y se ubica en la exigencia de su redefinición como trabajo, como actividad práctica, cuyo despliegue liberado del trabajo alienado haría estallar la división jerárquica entre trabajo social y creación artística. En otras palabras, esta redefinición dislocaría la estructura social que diferencia entre artistas y no artistas así como todos aquellos discursos instrumentales a la subjetividad burguesa y a la cultura del capitalismo, abriendo una oportunidad para la reconfiguración de los procesos productivos en un sentido democrático.

En La ideología alemana, escrita entre 1845 y I846, a poco más de 50 años de distancia de la Crítica del juicio, Marx denunció la existencia de los artis-

72. Kant, Critica del juicio, 335, 9 4I.

73. Beuys, "Discurso sobre el propio país", en Joseph Beuys, ed. Klüser, 20I. La idea también fue enunciada claramente por Steiner, www.emagister.com, 30. 
tas como producto de las limitaciones impuestas al desarrollo profesional de las personas por su supeditación a la división del trabajo: "La concentración exclusiva del talento artístico en individuos únicos y la consiguiente supresión de esas dotes en la gran masa es una consecuencia de la división del trabajo" ${ }^{74}$ Marx afirmó, en consecuencia, la socialización del talento en la futura sociedad comunista: "En una sociedad comunista no habrá pintores, sino a lo sumo hombres que, entre otras cosas, se ocupen también de pintar". Beuys afirma esta idea como un hecho del presente, es decir, opera él mismo un cambio en el concepto de artista: "Sólo acepto ser artista con la condición de que se considera a la persona otro tanto. Entonces, lógicamente, estoy de acuerdo, me apunto, pero en el fondo, no querría pertenecer a la agrupación de los artistas".75

La construcción de una economía de las capacidades que pudiera redefinir el sentido del trabajo y las condiciones de su realización supone igualmente la emergencia de un nuevo sujeto. Por ello Beuys afirma: "La cuestión de la estética es la cuestión del hombre" $7^{6}$ Confía en que el trabajo sea reconocido y experimentado individual y colectivamente como experiencia histórica creadora: "a lo que se hace referencia es a la actividad en cada uno de los lugares de trabajo, y puede referirse tanto a la actividad de una enfermera o a la capacidad de un agricultor como potencia configuradora y reconocerlas como una posición artística determinada" ${ }^{77}$ Para él, entonces, a través del trabajo los hombres reciben su "posicionalidad” histórica, o, en palabras de Marcuse:

El hombre que está manejando una máquina, el que arranca carbón en la mina, el dependiente tras el mostrador, el que forma parte como funcionario de un sistema o aparato burocrático, el que enseña como científico, en todos y cada uno de estos casos, ha salido de la esfera propia del sí mismo, colocándose en una posición muy determinada [...] a partir de la cual le está dada la posibilidad de existencia, de aceptación o de alteración de la situación..$^{78}$

74. Carl Marx y Federico Engels, La ideología alemana (México: Ediciones de Cultura Popular, 1974), 470 .

75. José Lebrero Stäls, "Entrevista con Joseph Beuys", Lápiz, núm. 27 (Madrid: 1985): I2I.

76. "Deviner espace avec introspecteur, interview de Gaya Goldcymer et Max Reithmann", en Beuys, Par la présent, I23.

77. Beuys, "Discurso sobre el propio país", en Joseph Beuys, ed. Klüser, 206.

78. Herbert Marcuse, "Acerca de los fundamentos filosóficos del concepto de trabajo", en Ética de la revolución (Madrid: Taurus, 1969), 38. 
Así, por el trabajo se sitúa el hombre dentro de determinado horizonte de posibilidades y su existencia recibe una posición histórica. Para Beuys esta posición debe ser reconocida como "artística" en la medida en que en el trabajo los seres humanos se asumen como creadores y toman conciencia de sus propias capacidades y de su relación con el tiempo futuro como posibilidad concreta. Dicho de otro modo, la autoconciencia de las propias capacidades, que hace del hombre un ser que se autorrealiza con los otros y con la naturaleza, define en y por el trabajo el sentido de la libertad como autodeterminación y autogestión. En ese reconocimiento reside la dimensión cognitiva del trabajo.

El trabajo es el espacio de realización del hombre como género, como vimos en el apartado anterior, y es, por ello, donde ocurre la realización personal y social. Beuys lo ejemplifica describiendo la organización de una fábrica de zapatos libre del dominio del capital y libre de la tutela del Estado: "En una empresa libre, naturalmente compete a los trabajadores determinar lo que hay que hacer, ya sea aquellos que tienen un puesto dirigente o un puesto operativo. Pero no he hablado de propietarios. He hablado de una empresa en la que todos cooperan, se dan a sí mismos una constitución y se administran ellos mismos" 79

La libertad sólo es posible, entonces, como definición autoconsciente de los fines por parte de los productores asociados que regulen el trabajo de forma racional, evitando destruir la naturaleza, y lo dirijan bajo el control compartido de todos. Veamos cómo lo enuncia el propio Marx:

La libertad, en este terreno, sólo puede consistir en que el hombre socializado, los productores asociados, regulen racionalmente éste su intercambio de materias con la naturaleza, lo pongan bajo su control común en lugar de dejarse dominar por él como por un poder ciego y lo lleven a cabo con el menor gasto posible de fuerzas y en las condiciones más adecuadas y más dignas de su naturaleza humana.

Y prosigue: "Pero, con todo ello, siempre seguirá siendo éste un reino de la necesidad. Al otro lado de sus fronteras comienza el despliegue de las fuerzas humanas que se considera como fin en sí, el verdadero reino de la libertad, que sin embargo sólo puede florecer tomando como base aquel reino de la necesidad $[\ldots] "$ ". 80

79. Beuys, "Discurso sobre el propio país", en Joseph Beuys, ed. Klüser, 2 I3.

8o. Lo omitido al final de la cita es: "La condición fundamental para ello es la reducción de la jornada de trabajo", Marx, El capital, 759. 
Como se ve, Beuys está de acuerdo con Marx al afirmar que el ámbito de la libertad sólo puede consistir en la abolición de la propiedad privada, es decir, en una organización del trabajo basada en una regulación racional de las relaciones de los seres humanos entre sí y de su metabolismo con la naturaleza. En consecuencia, la realización de la libertad no se sitúa en "un más allá” de la producción material; no se inicia donde supuestamente terminaría la necesidad. La soberanía reside en los individuos que, libremente asociados, con su actividad producen el mundo histórico atendiendo a sus necesidades y desplegando sus capacidades con apego a la vida. El principio de "calor", ese afecto productivo que hace posible la comunicicón y que posee un elemento erótico que impulsa la regeneración de los procesos sociales, alcanza su verdadera dimensión en la agencia. Por esa razón Beuys declaró que el proyecto de la cristiandad — supuestamente basado en el amor y los afectos productivos-, no había sido realizado: "lo que entendemos por democracia directa, o sea la que quiere colmar la necesidad que tiene el ser humano de libertad, igualdad y de fraternidad, es lo que consideramos el comienzo del cristianismo". ${ }^{81}$

\section{Democracia}

En una Alemania Federal cuya economía de mercado comenzó a mostrar en los años setenta signos de malestar, dividida por el muro soviético y en vecindad con el llamado socialismo real, la apuesta política de Beuys no fue por el proletariado como sujeto revolucionario, sino por la ciudadanía. Beuys apostó por las formas de organización correspondientes con iniciativas de participación ciudadana propias de la democracia y por las formas de subjetivación que éstas posibilitan. Esas formas de organización cívica se diversificaron en la República Federal de Alemania en los años posteriores a la disolución del movimiento estudiantil iniciado en 1967 y en ellas Beuys identificó la posibilidad concreta para vincular su programa artístico a las tendencias progresistas presentes en la sociedad en orden a construir una vanguardia también extendida. ${ }^{82}$

8I. Bodenmann-Ritter, Joseph Beuys, 68. Véase también Mennekes, Joseph Beuys, 80.

82. En ese sentido me parece equivocada la afirmación de Robin Lenman, John Osborne y Eda Sagarra de que, por haber buscado una "tercera vía" entre el socialismo y el capitalismo, Beuys forma parte del grupo de artistas que habrían rechazado la vida comunitaria (Gemeinschaft) en la moderna sociedad urbana a favor de la sociedad agraria. Véase, German Cultural Studies. An Introduction, ed. Rob Burns (Nueva York: Oxford University Press, 
Así como la ampliación del arte supone la redefinición del concepto de capital y la liberación del trabajo, una economía de corte socialista, la idea de plástica social implica la reinvención de la política. Se trata de la superación de las tensiones entre Estado y ciudadanía, algo que en la circunstancia histórica específica de la República Federal de Alemania reviste particular importancia. Recordemos que después de la derrota en la segunda guerra mundial, la recuperación económica de esa parte de Alemania tuvo lugar a partir de la puesta en marcha de la economía social de mercado acompañada de la integración política y cultural con Europa, sobre la base del establecimiento de instituciones democráticas. ${ }^{83}$ Entre I87 I y 1949 se habían sucedido en Alemania cuatro regímenes políticos totalmente distintos. Desde la fundación del imperio en I871, el país sólo conoció la democracia durante el breve periodo de la República de Weimar, la cual fue liquidada por el nacionalsocialismo. Así pues, desde los años del imperio, la modernización económica había estado unida a la inestabilidad política. ${ }^{84}$ Después de la segunda guerra mundial, la experiencia de la democracia era una experiencia nueva. En la década de los años cincuenta la urgencia de la reconstrucción económica retrasó la difusión de las normas de participación ciudadana, por lo cual no fue sino hasta mediados de la década siguiente cuando ésta se produjo. ${ }^{85}$ Durante los años sesenta

I995), 2I. Para una explicación de esta idea, Blanca Gutiérrez Galindo, "La revolución somos todos", en Joseph Beuys (México: Museo Nacional de la Estampa-InBa 2012).

83. Tras el breve interludio de un gobierno militar por parte de los aliados se impuso en la parte oriental de Alemania un régimen comunista unipartidista, y en las tres zonas occidentales se llegó a la fundación de una democracia parlamentaria de base federal sustentada en La Ley Fundamental de I949. Sobre los procesos políticos llevados a cabo después de la segunda guerra mundial véase Walther Hubatsch, La cuestión alemana (Barcelona: Herder, I965). Un estudio detallado sobre el proceso de democratización de Alemania Federal en los años posteriores a la segunda guerra mundial y su integración con el mundo occidental es el de Denis Goeldel, Le tournant occidental de l'Allemagne après 1945. Contribution à l'histoire politique et culturelle de la RFA (Estrasburgo: Les Presses Universitaires de Strasbourg, 2005).

84. La Constitución del Imperio Alemán contenía sólo los principios de organización del Estado, pero carecía de un catálogo de derechos fundamentales. Por el contrario, la Constitución de Weimar contenía una combinación de elementos parlamentarios, plebiscitarios y presidenciales y establecía amplios derechos sociales, políticos y económicos fundamentales. Esta constitución establecía un sistema electoral basado en un sistema equitativo para la representación parlamentaria.

85. Óscar W. Gabriel, Cambio social y cultura política. El caso de la República Federal de Alemania (Barcelona: Gedisa, I990), I03. En este sentido es muy importante el libro de Karl Jaspers, Libertad y reunificación. Tareas de la politica alemana (Salamanca: Ediciones de la 
y setenta aparecieron las iniciativas ciudadanas (Bürgerinitiativen) y los llamados nuevos movimientos sociales o movimientos contestatarios (neue soziale Bewegungen), como la protesta estudiantil y la Oposición Extraparlamentaria (APO) (Ausserparlamentarische Opposition), el feminismo, las luchas ecológicas y los movimientos por la paz, que se propusieron objetivos de alcance social amplio y obtuvieron, sobre todo los últimos, pequeñas victorias a partir de la organización ciudadana. Todos ellos emergieron durante el periodo en que el SPD, Partido Socialdemócrata de Alemania (Sozialdemokratische Partei Deutschlands), estuvo al frente del gobierno, entre 1966 y 1982. La emergencia de los ciudadanos como agentes políticos es introducida por Beuys en el mundo del arte y el debate estético y, como ya indiqué, en ella ve la posibilidad concreta de realización de sus ambiciones artísticas. Obras como Oficina de la Organización para la Democracia Directa mediante Referéndum (1972), Bomba de miel en el lugar de trabajo (1977) y 7000 Robles (1982) son emblemáticas en este sentido.

Conviene recordar aquí que la llegada al poder de la socialdemocracia en coalición con la CDU, Unión Demócrata-Cristiana (Christlich-Demokratische Union) (I966-1969), y con los liberales de la csu, Unión Social-Cristiana (Christlich-Soziale Union) (I969-I982), representó un viraje en la economía de la República Federal de Alemania. El sostenido crecimiento económico posterior a la segunda guerra mundial se había interrumpido por la recesión de I966, por lo cual, con la finalidad de enfrentar esa recesión, los socialdemócratas modificaron los instrumentos de la política económica con la implantación de presupuestos keynesianos de gestión macroeconómica. Esto supuso el fin de la economía social de mercado (Soziale Marktwirtschaft), el modelo económico de la Guerra Fría impulsado por el democristiano Ludwig Erhard, ministro de Economía de Konrad Adenauer y primer ministro de 1963 a 1966. El creciente papel del Estado se tradujo en el aumento de gastos públicos: de 27 en I970 a 43 por ciento del PIB en I980. Los socialdemócratas pensaron que los mecanismos del mercado no eran suficientes por sí mismos para asegurar una expansión armónica y que la economía debía dirigirse de forma global. La búsqueda de estabilización se concentró en cuatro mecanismos: la ayuda del gobierno a inversión, producción y empleo; la cooperación de grupos de interés y el gobierno; la puesta en marcha por parte del gobierno de una estrategia de planificación a mediano plazo, y una reforma del fede-

Universidad de Salamanca, 1997 [1960]), en el cual revisa la historia de la Alemania Federal de posguerra y causa gran escándalo por oponerse a la unificación del país. 
ralismo, es decir, la redefinición de las relaciones financieras entre el Bund y los Länder. De esa manera la economía se recuperó. El crecimiento se elevó (7.3 por ciento en I968 y 8.2 en 1969), la inflación se redujo a I.5 por ciento y el presupuesto federal presentó un excedente de I 500 millones de marcos alemanes. ${ }^{86}$ No obstante, la gestión keynesiana sería contestada por la estanflación de los años setenta. En esos años el programa del spo habría de enfrentar la complejidad del cambio social que se venía gestando durante los años sesenta y se extendería durante los setenta, simultáneamente a las crisis del petróleo de 1973 y 1979.

Beuys no estuvo de acuerdo en que una mejor repartición del ingreso fuera la solución al problema del trabajo alienado. Consideró que la autogestión, como forma de organización del trabajo en fábricas, escuelas y universidades, sostiene el concepto de ciudadanía, el cual hace posible la participación en la vida pública a través de la acción autorregulada e inclusiva de todos. La autogestión, como acción de asociarse de los productores para darse a sí mismos sus propios fines, que tiene lugar en el mundo de la actividad práctica, posibilita la emergencia de formas de organización ciudadana que, afirma, hacen "impracticable" "al concepto de lo político". Con ello se refiere al sistema de los partidos políticos que considera parte de la maquinaria estatal.

El programa de Beuys, en consecuencia, está muy lejos de la liquidación de la política, como ha afirmado Eric Michaud en su afán por completar la ambición de Benjamin H.D. Buchloh de construir un Beuys nacionalsocialista. ${ }^{87}$ Como en el caso del capital, aquí es el concepto prevaleciente de lo

86. José María Díez Espino y Ricardo M. Martín de la Guardia, Historia contemporánea de Alemania, 1945-1995 (Madrid: Síntesis, I998), I45-I47.

87. Eric Michaud interpreta esta declaración como sigue: "Como lo hará más tarde Joseph Beuys declarando que su 'concepto ampliado de arte' volvía 'caduca la política', el nazismo no procedió a la 'identificación de lo político a lo estético', sino más bien a la supresión y a la destrucción de lo politico por el arte". "Ouvre d'art total et totalitarisme", en Galard, L'Oeuvre d'art total, 62. En su texto "Beuys, The Twinlight of the Idol", en Joseph Beuys. Mapping the Legacy, ed. Gene Ray (Nueva York: D.A.P./The John And Mable Ringling Museum of Art, 200I), Benjamin H.D. Buchloh abrió la indagación a la exploración, en el personaje Beuys, de las posibles secuelas de su adhesión a las juventudes nazis a los I7 años de edad, exploraciones que con frecuencia han intentado la descalificación de su obra recurriendo al uso de clichés nacionalistas. Esto ha dado lugar a una vertiente historiográfica empeñada en construir un Beuys nazi. En esa dirección se puede mencionar el libro de Frank Gieske y Albert Markert, Flieger, Filz, und Vaterland. Eine erweiterte Beuys-Biografie (Berlín: Elefantenpress, 1996), que focaliza la biografía de Beuys en el periodo nazi entre I933 y 1945; 
político el que es preciso repensar en el horizonte de su transformación, porque auspicia la dictadura del concepto hegemónico de capital inhibiendo el ejercicio de la soberanía popular, de la verdadera democracia. Por ello dice: "Cuanto más observo la cuestión en su esencia y en la descripción de lo ya dado, en la descripción del hombre como creador en sentido propio, veo que el hombre es soberano especialmente en el campo de las fuerzas de la democracia". 88

El concepto de arte ampliado propone que el hombre se convierta en un "yo decididor": "el soberano puede decidir sobre una constitución, y en una democracia habría que pedirle su parecer cuando haya que tomar una decisión vital para el pueblo. La instalación de armas nucleares en su territorio, por ejemplo. ¡Es al soberano a quien competería la decisión y no a los delegados de ese soberano!"89 Beuys alude aquí a la decisión de la Organización del Tratado del Atlántico Norte (OTAN) de reforzar sus efectivos con la instalación en Europa de 108 cohetes de alcance medio (Pershing II) y 464 misiles de crucero (Cruise) con motivo del recrudecimiento del enfrentamiento esteoeste en 1979. Ante el temor de un "desacoplamiento" militar entre Estados Unidos y el teatro de operaciones europeo, el canciller socialdemócrata Helmut Schmidt apoyó la instalación y contó con la aprobación del Partido Socialdemócrata. El movimiento pacifista contestó a la decisión y su activismo se materializó en el llamamiento de Krefeld, de noviembre de I980, que bajo el lema "La muerte atómica nos amenaza a todos — ningún misil atómico en Europa" dio origen al nuevo movimiento pacifista germano occidental. En

el artículo de Eric Michaud "De Fluxus à Beuys: la fascination du politique”, en L'Ouvre d'art totale, ed. Elie Konigson (París: Centre National de Recherche Scientifique, 2002), 29I-300. Eric Michaud es también autor de "The Ends of Art according to Beuys", October 45 (verano, 1988): 36-46. Igualmente el texto de Mari Dumett y Serge Gilbaut "Beuys el bullicioso. ¿'Subversivo o dirigente sectario?", Curare. Espacio crítico para las artes, núm. I3 (julio-diciembre, 1998): 8-3I. La mayoría de estos autores no ha hecho sino desarrollar las afirmaciones de Buchloh en torno a un "Beuys nacionalsocialista y fascista". En la misma línea se ubica Sandro Bocola en su libro El arte de la modernidad. Estructura y dinámica de su evolución de Goya a Beuys (Barcelona: Serbal, I999), 493-550. Un caso diferente es el de John F. Moffitt, quien en su libro Occultism in Avant Garde Art. The Case of Joseph Beuys (Londres: umi Research Press/Ann Arbor, I988) sostiene que la obra de Beuys se explica no sólo por ser la ekphrasis de las ideas de Steiner, sino también por la ideología völkisch, la cual habría aprendido durante su infancia.

88. Beuys, "Discurso sobre el propio país", en Joseph Beuys, ed. Klüser, 203.

89. Beuys, "Discurso sobre el propio país", en Joseph Beuys, ed. Klüser, 205. 


\section{36}

BLANCA GUTIÉRREZ GALINDO

seis meses el llamamiento fue firmado en 1980 por 800 ooo personas, en 1982 por dos millones y medio y el año siguiente por cinco millones..$^{90}$

Así pues, para Beuys la democracia parlamentaria es claramente insuficiente, de ahí su inconformidad con la política seguida por los Verdes, un partido en cuya fundación participó en 1979, pero que no tardó en incorporar, en sí mismo, "la contradicción entre el movimiento social y el sistema político que busca asegurar sobre todo la existencia del sistema político". ${ }^{91}$ Por ello, Beuys interpretó positivamente las acciones de iniciativas y movimientos ciudadanos como Greenpeace. $9^{22}$ Según sus propias declaraciones, no estuvo interesado en "redactar un programa político y decir: hay que hacerlo así", 93 sino en promover el surgimiento de nuevas organizaciones sociales:

Poco a poco acabaremos por transformar esa materia, lo que se llama política [...], en conceptos en los que cada cual se sienta miembro de la sociedad, un miembro que puede cooperar creativamente. De manera que la futura política sea más bien un arte. Y que los seres humanos sepan que estos conceptos se toman en su sentido más eminente, humano, artístico; que es interesante ocuparse de la materia, es decir, de cuestiones de economía, de derecho, de educación, de arte, de ciencia, etcétera. Que uno PIENSE acerca del organismo social en su conjunto, que participe en el

90. Jorge Riechmann, Los Verdes alemanes: historia y análisis de un experimento ecopacifista a finales del siglo XX (Granada: Comares, I994), I07. En I980 y 1982 tuvieron lugar numerosas manifestaciones en favor de la paz y el número de los objetores de conciencia aumentó de 40000 en 1973 a casi 70000 en 1983 . Veáse Díez Espino y Martín de la Guardia, Historia contemporánea, I8I-I82. En La guerra y la paz (Krieg und Frieden), película realizada precisamente en 1982, Alexander Kluge brinda un extraordinario retrato del clima psicológico y social que entre los alemanes occidentales provocó este episodio del recrudecimiento de la Guerra Fría. La dirección de esta película estuvo a cargo también de Volker Schlöndorff, Stefan Aust y Axel Engstfeld. En la elaboración del guión también participó Heinrich Böll. 91. Véase Habermas, "Entrevista con la New Left Review", en Ensayos políticos, 216-217. 92. "Esta confrontación socio-ecológica comienza con 'cada hombre es un artista', es decir, con el concepto de libertad, de creatividad orientada al conjunto de la sociedad. Ésta crea primero el trabajo socio-ecológico que permitirá suprimir de raíz los daños causados al medio ambiente. Téngase en cuenta que tales trabajos - los de Greenpeace, por ejemploson admirables y muy importantes. Todo el mundo debería apoyar a esta gente. No puedo subrayar suficientemente la importancia de este fenómeno; son grupos de los cuales no nos vamos a quejar." Joseph Beuys, "Discurso sobre el propio país", en Joseph Beuys, ed. Klüser, 212. Greenpeace fue fundada en Canadá en 197 I y en Alemania en 1980.

93. Bodenmann-Ritter, Joseph Beuys, Ioo. 
pensamiento, en la creación, como un ser humano. Y que no se deje eso en manos de unos pocos, que naturalmente sacan provecho propio del asunto. ${ }^{94}$

La redefinición del concepto de lo político supone que la libertad, privilegio del artista el cual, para Beuys, hace posible la realización de las capacidades en el trabajo y la asociación en la producción, se realiza también como libertad cívica: "hay dos cosas que debemos saber sobre nuestras necesidades: la libertad y los derechos engendrados por esa libertad". ${ }^{95} \mathrm{El}$ individuo soberano, el ciudadano, es el miembro de una comunidad regida por derechos y deberes que participa en la discusión de los problemas comunes y en la toma de decisiones. Sólo de esta manera, a través de la idea del "ser humano como criatura que se autodetermina”, es posible la constitución de la ciudadanía como agente político, como sujeto histórico, cuyo surgimiento representa para Beuys la posibilidad de operar una desviación en el rumbo de los procesos modernizadores en el capitalismo y el comunismo.

Así pues, de la misma manera que el trabajo no alienado está sujeto a la necesidad, la libertad está sujeta al dominio del derecho, por lo cual debe entenderse como libertad cívica en su sentido burgués. Esto demuestra la equivocación de Robert Storr cuando afirma que la ambición de Beuys fue "recuperar los elementos más alienados de la izquierda y reorientar sus energías hacia su propia visión de una nueva sociedad dedicada a la imaginación y milagrosamente equilibrada entre comunismo y capitalismo”. De esta manera habría "esperado disolver los antagonismos y las tendencias violentas alimentados por la Guerra Fría en Alemania en el fluido amniótico de su propia poética y trascendentalismo filosófico, ofreciendo una ideología de creatividad libre y sin trabas como alternativa a la ideología de la destrucción”. 96 Como he intentado mostrar, para Beuys la libertad tiene una clara dimensión pública, es decir, política, porque en el trabajo posibilita el despliegue de las capacidades humanas y en la vida pública organiza las formas de asociación entre individuos, lo cual hace posible la abolición del Estado. En otros términos, la libertad cívica hace posible una organización de la sociedad regida por los productores libremente asociados, los cuales extinguen la producción

94. Bodenmann-Ritter, Joseph Beuys, 8I.

95. Beuys, "Discurso sobre el propio país", en Joseph Beuys, ed. Klüser, 209.

96. Robert Storr, Gerhard Richter. Doubt and Belief in Painting (Nueva York: The Museum of Modern Art, 2003), 234-235. 
mercantilizada, derogan las jerarquías entre modalidades del trabajo y pueden, de esa manera, operar una socialización de las capacidades en la producción de valores de uso: "Nadie compra y nadie vende capacidades y trabajo. Todas las actividades conforme a sus ingresos son propiedad de la comunidad democrática de ciudadanos con igualdad de derechos". 97

\section{Plástica social}

Como Marx, Beuys afirma que el Estado es el representante de los intereses de las clases dominantes..$^{8}$ De ahí que reclame la necesidad de ciudadanizar las instituciones a él asociadas, tales como la educación y los medios de comunicación. Así lo hizo, por ejemplo, durante la inauguración de la Documenta 6 de 1977, donde se refirió a la dimensión pública de los medios de comunicación, haciendo un llamado a liberar a "la enseñanza, la enseñanza universitaria, la prensa, la radio, la televisión, la totalidad de la información, del dominio del Estado". ${ }^{9}$ Beuys estaba señalando, precisamente, la dimensión pública de la comunicación como un fenómeno constitutivo de las sociedades contemporáneas, la cual incumbe a los ciudadanos y de ninguna manera puede estar sometida a intereses económicos privados o a los del Estado.

Frente al Estado y la dictadura del capital, la actividad de Beuys persiguió la creación de la esfera pública (Offentlichkeit). De esta manera, el nuevo concepto de política con que el artista pretendió corregir el marxismo tiene su núcleo precisamente en la comunicación intersubjetiva y el intercambio simbólico. En obras como Oficina de la Organización para la Democracia Directa mediante Referéndum y Bomba de miel en el lugar de trabajo, Beuys redefinió la función del museo, sede de la conservación y difusión del arte en su condición

97. Beuys, "Llamamiento a la alternativa", en Joseph Beuys, ed. Klüser, 99.

98. "es la forma bajo la cual los individuos de una clase dominante hacen valer sus intereses comunes y en la que se condensa toda la sociedad civil de una época, se sigue de aquí que todas las instituciones comunes tienen como mediador al Estado y adquieren a través de él una forma política." Marx y Engels, La ideología alemana, 72.

99. Por iniciativa de Nam June Paik se transmitió vía satélite en una emisión realizada para la televisión internacional en la que participaron el propio Paik, Beuys y Douglas David. Véanse Documenta 6, disco I, 278, y Joseph Beuys, Films et videos (París: Centre Georges Pompidou, 1994), 66. Las intervenciones fueron publicadas íntegramente en Joseph Beuys. Documenta-Arbeit. Herausgegeben von Veit Loers, Pia Witzmann, Buch zur Ausstellung im Museum Friedericianum Kassel (Stuttgart: Canz, I993), I48. 
autónoma, convirtiéndolo en el lugar modelo para la elaboración pública de la relación entre creatividad y democracia. ${ }^{100}$

Desde el siglo Xvin el museo es uno de los componentes fundamentales de la institución del arte, el espacio en el que tiene lugar la experiencia especializada en el juicio estético sobre lo bello; es también donde el sujeto burgués accede a la experiencia de la unidad entre subjetividad y libertad. En Bomba de miel en el lugar de trabajo ${ }^{\mathrm{IOI}}$ Beuys llevó a cabo la reconfiguración del museo como el lugar de encuentro ciudadano capaz de ensanchar la esfera pública a través de la puesta en común de las percepciones, en la definición de los problemas y la coordinación de las acciones. Presentó el arte como un lugar común en el interior del cual es posible la confluencia de lo estético, lo cognitivo y lo ético. Entonces se produjeron en el museo conceptos y argumentos nuevos en un proceso comunicativo-discursivo dirigido a la toma de decisiones sobre la vida pública, o, dicho en los términos de Habermas, un proceso en el cual las interpretaciones cognoscitivas, las expectativas morales, las expresiones y las valoraciones encontraron una oportunidad para interrelacionarse. De esta manera, el museo pasó de ser


ceptos” elaborados por la ciudadanía, el nuevo agente de la transformación política en Alemania occidental.

Así pues, el programa artístico de Beuys se basó en una crítica de la alienación del trabajo y de la sujeción del Estado al concepto de capital; buscó una socialización y ciudadanización de la creatividad, es decir, su

Ioo. Más de 20 años después, en 200I, Hans Belting demandaría al museo contemporáneo que se convirtiera en un sitio de reflexión y discusión sobre los problemas comunes. Véase "Place of Reflection or Place of Sensation?", en The Discursive Museum, ed. Peter Noever (Viena: Hatje Cantz Publishers, 200I).

Ior. Véase mi tesis de Doctorado en Historia del Arte, "Joseph Beuys. Arte ampliado y plástica social” (México: Universidad Nacional Autónoma de México-Facultad de Filosofía y Letras, 2010).

I02. Véase el texto de Douglas Crimp "Sobre las ruinas del museo", en Hal Foster, La posmodernidad (México: Kairós, I980), 75-92.

I03. Con la exposición When Attitudes Become Form: Works-Concepts-Process-SituationsInformation. Live in your Head, Harald Szeemann logró convertir el museo en un lugar de experimentación artística, ya que los propios artistas instalaron su trabajo o lo realizaron in situ. Con Szeemann, el término "exposición” adquirió una elasticidad nunca vista. Véase la entrevista de Nathalie Heinich, Harald Szeemann. Un cas singulier (París: L'Echoppe, I996). En esa exposición, Beuys presentó Espacio de la Documenta. Esculturas y objetos de 1952 a 1957 . 
politización en los marcos de la democracia. La superación de lo político que se propuso opera, por tanto, en el doble registro del despliegue de las capacidades humanas reprimidas por el capitalismo y del ejercicio del diálogo y la acción inhibidos igualmente por las sociedades de consumo y los gobiernos totalitarios. \$े

N.B. Este artículo es parte de mi tesis de Doctorado en Historia del Arte, "Joseph Beuys. Arte ampliado y plástica social" (México: Universidad Nacional Autónoma de México-Facultad de Filosofía y Letras, 2010) cuya publicación en forma de libro preparo actualmente. 